\title{
Modelling physical and ecological processes in medium-to-large deep European perialpine lakes: a review
}

\author{
Claudia Dresti, ${ }^{1}$ Andrea Fenocchi, ${ }^{2 *}$ Diego Copetti ${ }^{3}$ \\ ${ }^{1}$ National Research Council, Water Research Institute, Largo Tonolli 50, 28922 Verbania Pallanza (VB); ${ }^{2}$ Department of Civil \\ Engineering and Architecture, University of Pavia, Via Ferrata 3, 27100 Pavia; ${ }^{3}$ National Research Council, Water Research Institute, \\ Via del Mulino 19, 20861 Brugherio (MB), Italy
}

\begin{abstract}
In this paper we review a significant sample of the modelling studies carried out on medium-to-large deep European perialpine lakes (MLDEPLs). The reviewed bibliographic corpus was obtained querying Elsevier's Scopus ${ }^{\circledR}$ database with a tailored search string on 8 January 2021. Results were filtered, accepting only journal papers written in English dealing with natural lakes having surface area $>10 \mathrm{~km}^{2}$. A list of 75 works was obtained, published between 1986 and 2021. Most studies have been carried out on Swiss lakes (44 out of 75 papers), Lake Geneva being the most investigated environment. A significant positive correlation was found between lake surface area and volume and the number of dedicated papers, suggesting that scientific attention is higher for environments characterised by large dimensions and relevant socio-economic interests. Both the number of papers and their citation count have experienced an exponential growth in time, pointing to a rising interest in quantitative modelling applications, but also to the increasing availability and ease of use of numerical modelling tools. Among the 75 selected papers, 55 employ a hydrodynamic driver, used alone or coupled with an ecological module, while the remnant 20 works adopt an ecological-only model. Among the papers employing hydrodynamic models, the use of three-dimensional (3D) drivers is surprisingly slightly more frequent (28 papers) than that of one-dimensional (1D) ones (26 papers), with almost all 3D applications having been published in the last 2011-2020 decade (24 papers). This reflects the interest on the hydrodynamic processes leading to the observed spatial heterogeneities in the biochemical properties of the MLDEPLs. However, coupling of ecological modules with 3D hydrodynamic drivers, to directly simulate these phenomena, is still restricted (2 papers) compared to that of 1D hydrodynamic drivers (8 papers), due to calibration and computational difficulties, which could be strongly reduced by future research achievements. Nevertheless, 1D models allow performing long-term prognoses considering multiple climate change and watershed management scenarios, due to their much smaller computational burden. The largest group of works dealing with ecological-only models (6 papers) is dedicated to applications of phosphorus budget models, which can above all be used to forecast variations in lake productivity in response to changes in the availability of the limiting nutrient.
\end{abstract}

\section{INTRODUCTION}

Medium-to-large deep European perialpine lakes (MLDEPLs) are lacustrine environments of glacial origin located at the northern and southern foothills of the European Alps (Tolotti et al., 2018). These lakes are important water sources, supporting different local economic sectors including tourism, fishing, agriculture and industry

Corresponding author: andrea.fenocchi@unipv.it

Key words: Hydrodynamic, ecological, coupled numerical models; 0D, 1D, 3D numerical models; stratification; nutrients; climate change; management.

Received: 9 June 2021.

Accepted: 5 October 2021.

This work is licensed under a Creative Commons Attribution NonCommercial 4.0 License (CC BY-NC 4.0).

${ }^{\circ}$ Copyright: the Author(s), 2021

Licensee PAGEPress, Italy

J. Limnol., 2021; 80(3):2041

DOI: 10.4081/jlimnol.2021.2041
(Salmaso et al., 2019, 2020). They are among the most studied and well-known lentic ecosystems in the world and have been the subject of two recent papers that reviewed the main research activities carried out on them (Salmaso et al., 2018, 2020). The MLDEPLs share similar morphometric features and climatic conditions and have been subjected to comparable anthropogenic stresses (Salmaso et al., 2003; Gallina et al., 2013). The economic development occurred after World War II caused generally increasing nutrient loadings with consequent trophic enrichment, worst conditions being reached around the mid-1980s (Salmaso and Mosello, 2010). The subsequent implementation of sewage systems and of wastewater treatment plants, combined with the abatement of phosphorus concentrations within detergents, allowed a reduction of phosphorus concentrations in their waters (Anneville et al., 2005; Rogora et al., 2018). This implied consistent re-oligotrophication of these ecosystems (Salmaso et al., 2020). Despite the clear improvement in their trophic status, in recent years the MLDEPLs have been subjected to massive blooms of harmful cyanobacteria species (Bresciani et al., 2018; Salmaso, 2019; Salmaso et al., 2020), some of which (e.g. Planktothrix rubescens) have successfully adapted to current mesotrophic conditions (Anneville et al., 2004). Climate change contributes to the intensification of such 
blooms (Paerl and Paul, 2012; Posch et al., 2012; Gallina et al., 2013; Yankova et al., 2017), through the warming of surface water and the increasing stability of the water column that have long been observed (Ambrosetti and Barbanti, 1999; Livingstone, 2003). These physical phenomena have been related to both global warming and to the leading modes of interannual atmospheric variability in the Northern Hemisphere, the East Atlantic (EA) pattern and the North Atlantic Oscillation (NAO) (Livingstone, 2003; Salmaso et al., 2014; Lepori and Roberts, 2015; Rogora et al., 2018).

The past, present and future evolution of the MLDEPLs has been explained and forecasted in the last decades through models. In this paper, we review a thorough sample of papers dealing with this topic, to determine the current state-of-the-art including limitations, problems and research prospects.

Conceptually, lake models can be divided into two main categories: i) statistical models and ii) processed-based models (Fornarelli et al., 2013). Statistical models consist of inferential relations between the predictor variables and the variables of interest such as nutrient and chlorophyll- $a$ (Chla) concentrations (Huszar et al., 2006). A recent evolution of this approach lies in the use of artificial-intelligence methods (Jung et al., 2010; García-Nieto et al., 2018), employing machine-learning (ML) techniques (e.g., support-vector-machine or tree-based models). Process-based numerical models instead simulate lake physical and biogeochemical processes through differential equations (Fornarelli et al., 2013; Vinçon-Leite and Casenave, 2019), which should ensure better model performances (Trolle et al., 2012; VinçonLeite and Casenave, 2019). Process-based models can deal with only lake physics (hydrodynamic models) or ecology (ecological models), or with both (coupled ecological-hydrodynamic models). In the latter case, the hydrodynamic model drives the mixing processes of the ecological variables (Trolle et al., 2012).

One-dimensional (1D) hydrodynamic models represent the horizontally averaged physics of the lake water column, i.e. mainly water temperature dynamics, assuming that horizontal gradients are negligible. This is legitimate for deep stratified basins, in which horizontal mixing is much faster than vertical mixing (Perroud et al., 2009; Rinke et al., 2010). Two-dimensional (2D) models in the horizontal plane are restricted to shallow, vertically mixed basins (Fragoso et al., 2008; Huang et al., 2012; Fenocchi et al., 2016), whereas 2D models in the vertical plane are suitable for elongated reservoirs in narrow valleys (Cole and Wells, 2013). Two-dimensional models, therefore, are not suitable for the MLDEPLs. Three-dimensional (3D) hydrodynamic models allow solving circulation processes with spatial and temporal continuity (Caramatti et al., 2020). These models can capture the spatial variability of physical and biogeochemical processes, yet they require relevant computational resources as well as extensive field measurements, since they must be calibrated and validated at multiple stations (Baracchini et al., 2020).

Ecological-only models lack a dynamic physical description, being thus called zero-dimensional (0D) or box models (Nyholm, 1978). In those models, the lake water column is represented through a single layer, or, to mimic stratification, through 2-3 layers whose thickness and physical properties are fixed a priori (Dietzel and Reichert, 2012; Dietzel et al., 2013). The most complete ecological models, being them isolated or coupled to a hydrodynamic driver, simulate the food chain originating and ending with nutrients after the decomposition of living organisms, reproducing the underlying dissolved oxygen (DO), carbon (C), nitrogen (N), phosphorus (P) and silica $\left(\mathrm{SiO}_{2}\right)$ biogeochemical cycles (Hipsey et al., 2013).

\section{METHODS}

The bibliographic search was carried out using Elsevier's Scopus ${ }^{\circledR}$ database. The following query was employed, looking for specific words present in the title (TITLE), abstract (ABS) or keywords (KEY) of the database entries:

TITLE-ABS-KEY ((perialpine OR peri-alpine OR prealpine $O R$ pre-alpine $O R$ subalpine $O R$ sub-alpine $O R$ alpine OR Alps OR France OR French OR Switzerland OR Swiss OR Italy OR Italian OR Austria OR Austrian OR Germany OR German) AND (lake OR basin) AND (hydrodynamic OR hydrodynamics OR thermodynamic OR thermodynamics OR ecology OR ecological OR ecologic OR ecosystem) AND (model OR modelling))

To be made part of the reviewed bibliographic corpus, a paper had to include in the mentioned fields at least one word for each of the 4 word groups separated by the AND Boolean operator. Manual addition of further works was not performed. The query was submitted to Scopus ${ }^{\circledR}$ on 8 January 2021, returning 1883 entries. These were filtered to include only journal papers in English dealing with models of natural perialpine lakes having surface area $>10$ $\mathrm{km}^{2}$. The restriction to journal papers in English was established to maximise the availability and intelligibility of the reviewed bibliographic corpus, books and national journals being generally more difficult to obtain from library services. This choice affects retrieval of older scientific production, as in the past it was common to publish research in books or in national journals (e.g., the Italian "Memorie/Documenta dell'Istituto Italiano di Idrobiologia", the German "Archiv für Hydrobiologie", the Swiss "Schweizerische Zeitschrift für Hydrologie" or the French "La Houille Blanche"). The constraint to natural lakes having surface area $>10 \mathrm{~km}^{2}$ was introduced to consider 
only models of basins with similar features, leaving out peculiar environments such as ponds or high-mountain reservoirs. In the end, 75 papers fulfilled all our requirements, being listed in Tab. 1 .
We designed the research query to be: i) as inclusive as possible to minimise shortcomings, hence the many synonyms and alternatives separated by the OR Boolean operator; ii) precise enough to limit the subsequent man-

Tab. 1. Papers included in the reviewed bibliographic corpus, with indication of the studied lakes, the model types and the employed codes.

\begin{tabular}{|c|c|c|c|}
\hline Paper & Lake & Model type & Employed code \\
\hline Rossi et al. (1986) & Lugano & 0D ecosystem & own \\
\hline Salvadè et al. (1992) & Lugano & surface seiche / internal seiche / 3D & own / own / own \\
\hline Panizzuti and Tartari (1995) & Orta & 1D coupled & own \\
\hline Vinçon-Leite et al. (1995) & Bourget & 1D coupled & own \\
\hline Joehnk and Umlauf (2001) & Ammer & 1D coupled & own \\
\hline Omlin et al. (2001a) & Zürich & 0D ecosystem & own inside AQUASIM \\
\hline Omlin et al. (2001b) & Zürich & 0D ecosystem & own inside AQUASIM \\
\hline Baudo (2002) & Orta & 0D stochastic population growth & own \\
\hline Enz et al. (2002) & Hallwil & 0D fish population dynamics & own inside STELLA \\
\hline Peeters et al. (2002) & Zürich & $1 \mathrm{D}$ & SIMSTRAT \\
\hline Buerge et al. (2003) & Zürich & OD caffeine cycle & own inside AQUASIM \\
\hline Livingstone (2003) & Zürich & OD thermodynamic & own \\
\hline Danis et al. (2004) & Ammer / Annecy & $1 \mathrm{D}$ & own \\
\hline Schauser et al. (2004) & Sempach & 0D P budget & own \\
\hline Schauser et al. (2006) & Sempach & 0D P budget & own \\
\hline Dueri et al. (2009) & Maggiore & 1D coupled & COHERENS \\
\hline Janjua and Gerdeaux (2009) & Annecy & 0D ecosystem & own inside Ecopath with Ecosim \\
\hline Mari et al. (2009) & Garda & 3D coupled & own \\
\hline Morillo et al. (2009) & Como & $3 \mathrm{D}$ & ELCOM \\
\hline Bryhn et al. (2010) & Bourget & 0D P budget & own \\
\hline Laborde et al. (2010) & Como & $3 \mathrm{D}$ & ELCOM \\
\hline Cuypers et al. (2011) & Bourget & internal seiche & own \\
\hline Saha et al. (2011) & Constance & $3 \mathrm{D}$ & ELCOM \\
\hline Ambrosetti et al. (2012) & Maggiore & $3 \mathrm{D}$ & own \\
\hline Dietzel and Reichert (2012) & Zürich & 0D ecosystem & own inside AQUASIM \\
\hline Laborde et al. (2012) & Como & $3 \mathrm{D}$ & ELCOM \\
\hline Weinberger and Vetter (2012) & Ammer & $1 \mathrm{D}$ & DYRESM \\
\hline Bonvin et al. (2013) & Geneva & 3D coupled & Delft3D-own photolysis \\
\hline Finger et al. (2013) & Lucerne & 0D phytoplankton interpolation & own \\
\hline Moschet et al. (2013) & Constance & 0D micropollutant budget & MASAS \\
\hline Razmi et al. (2013) & Geneva & $3 \mathrm{D}$ & Delft3D \\
\hline Vilhena et al. (2013) & Iseo & $3 \mathrm{D}$ & ELCOM non-hydrostatic / ELCOM \\
\hline Bueche and Vetter (2014a) & Ammer & $1 \mathrm{D}$ & DYRESM \\
\hline Bueche and Vetter (2014b) & Ammer & $1 \mathrm{D}$ & DYRESM \\
\hline Müller et al. (2014) & Hallwil / Sempach & 0D P budget & Vollenweider (1975) \\
\hline Pilotti et al. (2014a) & Iseo & $1 \mathrm{D}$ & DYRESM \\
\hline Pilotti et al. (2014b) & Iseo & $3 \mathrm{D}$ & ELCOM \\
\hline Razmi et al. (2014) & Geneva & $3 \mathrm{D}$ & Delft3D \\
\hline Vinçon-Leite et al. (2014) & Bourget & $1 \mathrm{D}$ & own \\
\hline Weinberger and Vetter (2014) & Ammer & $1 \mathrm{D}$ & DYRESM \\
\hline Bueche and Vetter (2015) & Ammer & $1 \mathrm{D}$ & DYRESM \\
\hline Straile et al. (2015) & Constance & $1 \mathrm{D}$ & SIMSTRAT \\
\hline
\end{tabular}


ual selection of results. The first word group addresses the geographical location, thus including the word "perialpine" and its synonyms, "alpine" and "Alps" themselves, plus the names and the related adjectives of the countries that are crossed by the Alps and have lakes fulfilling our criteria (Slovenia and Liechtenstein are hence not included). The third word group refers to the types of models relevant for this review (i.e., separate or coupled hydrodynamic and ecological models). Such specification is needed as the word "model" is often used in limnological papers to describe case studies whose analysis would lead to conclusions which can be broadened to similar environments and for the application of statistical techniques to analyse field data.

\section{REVIEW}

\section{Statistics of the bibliographic corpus}

Tab. 2 lists the 34 natural European perialpine lakes having surface area $>10 \mathrm{~km}^{2}$, with the number of papers dealing with each of them in the reviewed bibliographic

Tab. 1. Continued from previous page.

\begin{tabular}{|c|c|c|c|}
\hline Paper & Lake & Model type & Employed code \\
\hline Valerio et al. (2015) & Iseo & $1 \mathrm{D}$ & DYRESM \\
\hline Minella et al. (2016) & Garda / Geneva / Iseo & OD photochemistry & APEX \\
\hline Bueche et al. (2017) & Ammer & 1D & GLM \\
\hline Fenocchi et al. (2017) & Maggiore & $1 \mathrm{D}$ & GLM \\
\hline Franchini et al. (2017) & Lugano & 0D phytoplankton interpolation & own \\
\hline Gallina et al. (2017) & Geneva & 0D ML phytoplankton prediction & own \\
\hline Kerimoglu et al. (2017) & Bourget & 1D coupled & GOTM-FABM-own biogeochemical \\
\hline Lepori and Roberts (2017) & Lugano & 0D P budget & Nürnberg (1998) \\
\hline Råman Vinnå et al. (2017) & Biel & $1 \mathrm{D} / 3 \mathrm{D}$ & SIMSTRAT / Delft3D \\
\hline Valerio et al. (2017) & Iseo & 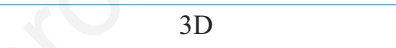 & ELCOM \\
\hline Amadori et al. (2018) & Garda & $3 \mathrm{D}$ & Delft3D \\
\hline Fenocchi et al. (2018) & Maggiore & $1 \mathrm{D}$ & GLM \\
\hline Mirbach and Lang (2018) & Constance & $3 \mathrm{D}$ & ELCOM \\
\hline Scheu et al. (2018) & Maggiore & $3 \mathrm{D}$ & SUNTANS \\
\hline Schwefel et al. (2018) & Geneva & $3 \mathrm{D}$ & Delft3D \\
\hline Soulignac et al. (2018) & Geneva & $3 \mathrm{D}$ & Delft3D \\
\hline Dissanayake et al. (2019) & Constance & $3 \mathrm{D}$ & ELCOM / Delft3D \\
\hline Fenocchi et al. (2019) & Maggiore & 1D coupled & GLM-AED2 \\
\hline Gaudard et al. (2019a) & $\begin{array}{c}\text { Biel / Brienz / Constance / } \\
\text { Geneva / Hallwil / Lucerne / } \\
\text { Lugano / Maggiore / Murten / } \\
\text { Neuchâtel / Sempach / Thun / } \\
\text { Walen / Zug / Zürich }\end{array}$ & 1D & SIMSTRAT \\
\hline Gaudard et al. (2019b) & Constance / Zürich & $1 \mathrm{D}$ & SIMSTRAT \\
\hline Nouchi et al. (2019) & Geneva & $3 \mathrm{D}$ & Delft3D \\
\hline Piccolroaz et al. (2019) & Garda & $3 \mathrm{D}$ & Delft3D \\
\hline Ulloa et al. (2019) & Lucerne & $3 \mathrm{D}$ & own \\
\hline Amadori et al. (2020) & Garda & $3 \mathrm{D}$ & Delft3D \\
\hline Baracchini et al. (2020) & Geneva & $3 \mathrm{D}$ & Delft3D \\
\hline Bueche et al. (2020) & Ammer & $1 \mathrm{D}$ & GLM \\
\hline Caramatti et al. (2020) & Constance & $3 \mathrm{D}$ & AEM3D \\
\hline Copetti et al. (2020) & Como & $3 \mathrm{D}$ & ELCOM \\
\hline Derot et al. (2020) & Geneva & 0D ML phytoplankton prediction & own \\
\hline Fenocchi et al. (2020) & Maggiore & 1D coupled & GLM-AED2 \\
\hline Lemaire et al. (2020) & Annecy & $0 \mathrm{D}$ ecosystem & own inside Ecopath with Ecosim \\
\hline Råman Vinnå et al. (2020) & Biel & $3 \mathrm{D}$ & Delft3D \\
\hline Krishna et al. (2021) & Geneva & 1D coupled & GOTM-FABM-ERGOM \\
\hline
\end{tabular}


corpus, the lake country(ies), and the main morphometric properties. For multi-basin lakes (Lake Constance, Lake Lucerne, Lake Lugano, Lake Zürich), we do not distinguish between their individual basins for simplicity. A map of these perialpine lakes is given in Fig. 1, in which the basins included as case studies in the works of the bibliographic corpus are distinguished from the missing ones. Swiss lakes clearly received the widest attention, being the object of 44 out of 75 papers, with 60 case studies, Lake Geneva being the most investigated basin. All the Swiss lakes fulfilling our selection criteria are the object of at least one paper in- side the bibliographic corpus. The great attention given to Swiss lakes should be attributed to the consolidated tradition of limnological research in Switzerland, motivated by the socio-economic relevance held by the many lakes present in such country, which has no access to the sea, thus channelling national aquatic science towards inland waters. Italian and French lakes are significantly represented in the bibliographic corpus. Among the Italian MLDEPLs, only the smallest Lake Idro and Lake Varese are not addressed. A clear West/East separation yet emerges from Fig. 1, as no German lakes apart from Lake Constance and Lake

Tab. 2. Natural European deep perialpine lakes with surface area $>10 \mathrm{~km}^{2}$ (MLDEPLs), with the number of papers dealing with each of them in the reviewed bibliographic corpus, the lake country(ies) and the main morphometric properties (obtained from the German version of Wikipedia).

\begin{tabular}{|c|c|c|c|c|c|}
\hline Lake & Papers & Country & Area $\left(\mathrm{km}^{2}\right)$ & Volume $\left(\mathrm{km}^{3}\right)$ & Max. depth (m) \\
\hline Geneva & 12 & Switzerland / France & 581.3 & 89.9 & 310 \\
\hline Ammer & 9 & Germany & 46.6 & 1.8 & 81 \\
\hline Constance & 8 & Germany / Switzerland / Austria & 536.0 & 48.0 & 251 \\
\hline Maggiore & 8 & Italy / Switzerland & 212.3 & 37.1 & 372 \\
\hline Zürich & 8 & Switzerland & 90.1 & 3.9 & 136 \\
\hline Iseo & 6 & Italy & 65.3 & 8.1 & 251 \\
\hline Bourget & 5 & France & 44.5 & 3.6 & 145 \\
\hline Garda & 5 & Italy & 370.0 & 49.3 & 346 \\
\hline Lugano & 5 & Switzerland / Italy & 48.7 & 5.9 & 288 \\
\hline Como & 4 & Italy & 146.0 & 22.5 & 425 \\
\hline Sempach & 4 & Switzerland & 14.5 & 0.7 & 87 \\
\hline Annecy & 3 & France & 27.6 & 1.1 & 82 \\
\hline Biel & 3 & Switzerland & 39.8 & 1.2 & 74 \\
\hline Hallwil & 3 & Switzerland & 10.3 & 0.2 & 47 \\
\hline Lucerne & 3 & Switzerland & 113.6 & 11.8 & 214 \\
\hline Orta & 2 & Italy & 18.2 & 1.3 & 143 \\
\hline Brienz & 1 & Switzerland & 29.8 & 5.2 & 261 \\
\hline Murten & 1 & Switzerland & 23.0 & 0.6 & 46 \\
\hline Neuchâtel & 1 & Switzerland & 217.9 & 14.2 & 153 \\
\hline Thun & 1 & Switzerland & 48.4 & 6.5 & 217 \\
\hline Walen & 1 & Switzerland & 24.1 & 2.5 & 150 \\
\hline Zug & 1 & Switzerland & 38.3 & 3.2 & 198 \\
\hline Atter & 0 & Austria & 46.2 & 3.9 & 169 \\
\hline Chiem & 0 & Germany & 79.9 & 2.0 & 73 \\
\hline Idro & 0 & Italy & 11.0 & 0.6 & 122 \\
\hline Millstatt & 0 & Austria & 13.3 & 1.2 & 141 \\
\hline Mond & 0 & Austria & 13.8 & 0.5 & 68 \\
\hline Ossiach & 0 & Austria & 10.8 & 0.2 & 53 \\
\hline Starnberg & 0 & Germany & 56.4 & 3.0 & 128 \\
\hline Traun & 0 & Austria & 24.4 & 2.3 & 191 \\
\hline Varese & 0 & Italy & 15.0 & 0.2 & 26 \\
\hline Walchen & 0 & Germany & 16.3 & 1.3 & 190 \\
\hline Wolfgang & 0 & Austria & 12.8 & 0.7 & 114 \\
\hline Wörth & 0 & Austria & 19.4 & 0.8 & 85 \\
\hline
\end{tabular}


Ammer and no Austrian Lakes apart from Lake Constance are dealt within the bibliographic corpus, leaving out 3 and 6 MLDEPLs, respectively. A significant correlation was found between the number of papers dealing with each lake and both lake surface area $(r=0.66, \mathrm{p}<0.001)$ and volume $(r=0.68, \mathrm{p}<0.001)$, showing that larger lakes attract more research attention, likely due to their higher socio-economic relevance.

As of 8 January 2021, the 75 reviewed papers attained 1954 citations, i.e., on average $\sim 26$ citations per article. The works with more than 100 citations are: Buerge et al. (2003) with 500 citations, Livingstone (2003) with 280 citations, Peeters et al. (2002) with 128 citations and Omlin et al. (2001a) with 121 citations. These were pub- lished at the latest in 2003, suggesting that both quality and age of the papers contribute to the citation count. Considering the whole bibliographic corpus, both the number of published papers and of citations per year have experienced an exponential growth in time (Fig. 2). Such growth is even more striking with data aggregation: for 19862010 there are 4 papers and 10 citations, for the decade 2001-2010 there are 17 papers and 355 citations, while for the last 2011-2020 decade there are 53 papers and 1557 citations.

Not surprisingly, the most popular journal for the selected works is Ecological Modelling (13 papers) followed by the Journal of Limnology and Water Resources Research (5 papers each).

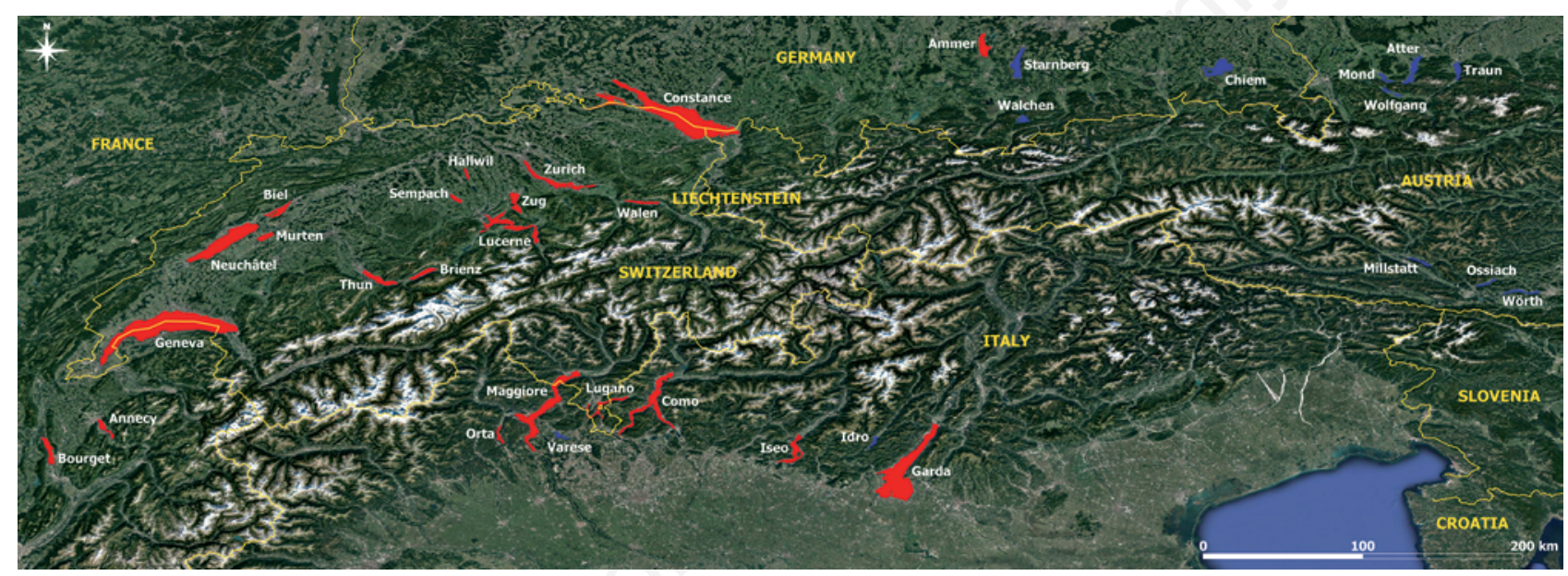

Fig. 1. Map of the 34 natural European deep perialpine lakes with surface area $>10 \mathrm{~km}^{2}$ (MLDEPLs): the lakes employed as case studies in the papers of the reviewed bibliographic corpus are filled in red, the neglected ones in blue (lake polygons were obtained from the HydroLAKES database (Messager et al., 2016), international boundaries were retrieved from the Eurostat geographical database, the ortophoto is courtesy of Google).

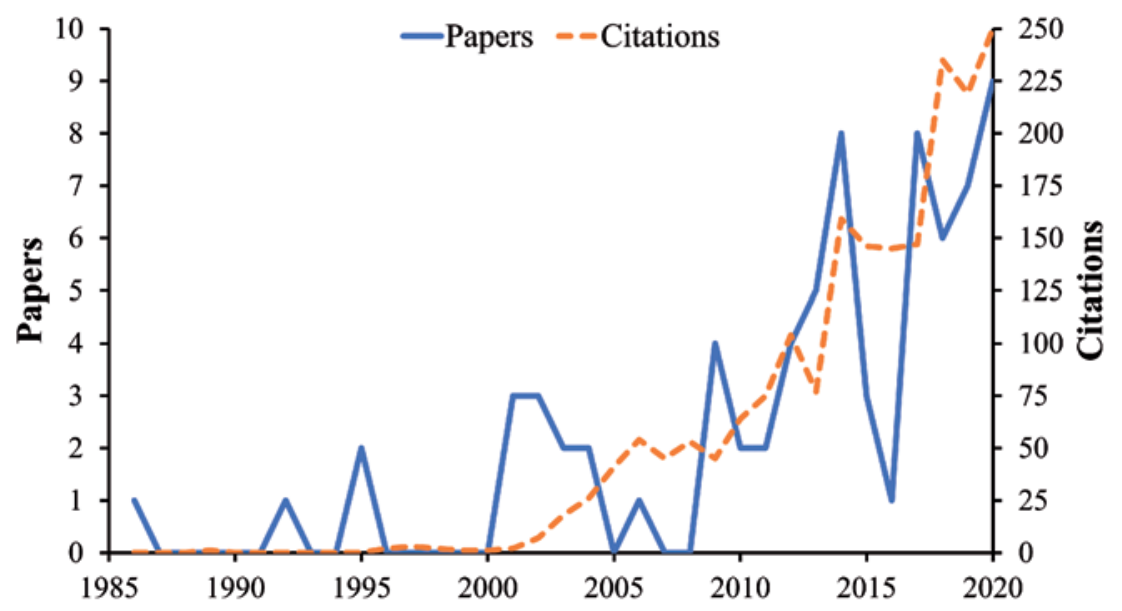

Fig. 2. Number of papers and citations per year for the reviewed bibliographic corpus. 


\section{D models}

The bibliographic corpus includes 26 papers with applications of 1D models, 18 employing a hydrodynamiconly setup and 8 adopting a coupled ecologicalhydrodynamic layout.

\section{Hydrodynamic models}

Among 1D hydrodynamic model applications, 7 papers employed DYRESM (DYnamics REservoir Simulation Model; Imberger et al., 1978; Imberger and Patterson, 1981). This model adopts a Lagrangian approach, with layers along the vertical joining and separating at each time step according to mixing and buoyancy forces. A mixed-layer approach is employed for turbulence closure.

Five of the papers adopting DYRESM deal with Lake Ammer. Weinberger and Vetter (2012) calibrated and validated the simulation of the vertical temperature profile in the lake for 2004-2007. Preliminary simulations of the 2041-2050 period were then performed, employing meteorological data from the regional climate model (RCM) REMO (Jacob et al., 2007) for the IPCC emission scenario A1B. These climate-change simulations were developed in Weinberger and Vetter (2014), using REMO and DYRESM to estimate the heat content and the thermal stability of the water column of Lake Ammer for 20412050. In Bueche and Vetter (2015), results of the RCM WETTREG (Spekat et al., 2010) were used to feed a DYRESM simulation of the 2042-2050 period, which was then compared to one of 2002-2010 to detect the impact of climate change. An extension of the stratified period and an increase of the metalimnion thickness in summer were identified. The relevance of groundwater inflows on the vertical thermal structure of Lake Ammer was studied in Bueche and Vetter (2014a). The inclusion in the model of a subsurface inflow based on available groundwater data effectively improved the reproduction of the observed water temperature profile. Bueche and Vetter (2014b) last analysed model performances under synthetic variations of the meteorological variables, concluding that DYRESM can reproduce long-term changes in water temperature due to climate change (see also Copetti et al., 2013).

The two other papers employing DYRESM concern Lake Iseo. In Pilotti et al. (2014a), DYRESM was applied to verify the results obtained by a simple non-parametric model estimating water age distribution in stratified lakes. Valerio et al. (2015) instead used DYRESM to assess the impact of climate change on Lake Iseo. First, they calibrated the model over 2010 and validated it over 19952009, showing that the main thermal features were reproduced, except for the seasonal variations in the 50$150 \mathrm{~m}$ layer. Then, they ran a single continuous 20112050 simulation, forced by a climatic-hydrological model
(Barontini et al., 2009), highlighting a differential warming rate (Livingstone, 2003) among the epilimnion $\left(0.02^{\circ} \mathrm{C} /\right.$ year $)$, the metalimnion $\left(0.015^{\circ} \mathrm{C} /\right.$ year $)$ and the hypolimnion $\left(0.009^{\circ} \mathrm{C} /\right.$ year $)$.

Four papers applied the General Lake Model (GLM; Hipsey et al., 2019). GLM originated from DYRESM, employing most of its basic algorithms, yet it has since been improved and expanded. Two papers employing GLM deal with Lake Ammer. In Bueche et al. (2017), GLM v2.2.0 beta 1 was calibrated and validated, finding better results than those obtained with DYRESM in previous works for the same lake in the epilimnion and in the hypolimnion. The capabilities of reproducing ice cover and heatwave events were also tested. Bueche et al. (2020) presented the open-source R-based graphical user interface (GUI) for GLM glmGUI, which includes tools for Monte Carlo autocalibration and parameter sensitivity analysis, testing those features over Lake Ammer.

The other two GLM papers concern Lake Maggiore. Fenocchi et al. (2017) carried out a study aimed at evaluating the differences in the reproduction of the vertical thermal structure by two different model configurations, one with an enclosed-lake and fixed-level approximation, considering atmospheric heat fluxes only, and another one considering riverine throughflows and implementing the hydrological balance. Their results show that a simpler model neglecting throughflows can reproduce the relevant thermal evolution of a lake with significant inflow contributions as Lake Maggiore, at the cost of adopting an unrealistically low light extinction coefficient to mimic riverine heat penetration. The use of the more complete model led to more accurate predictions in the lower metalimnion and upper hypolimnion, where inflows intrude during most of the year. Fenocchi et al. (2018) employed GLM to estimate the evolution of the thermal structure of Lake Maggiore under the Swiss climate change scenarios CH2011 (CH2011, 2011) for the period 2016-2085. They adopted the enclosed-lake and fixed-level approximation presented in the previous study and performed for each CH2011 scenario of air temperature warming multiple simulations, having produced random daily series of input meteorological variables through the Vector-Autoregressive Weather Generator (VG) (Schlabing et al., 2014). The statistical analysis of results over the manifold realisations for each scenario allowed removing the effects of the random occurrence of complete-mixing events on single simulations. The work concluded that Lake Maggiore would gradually pass from the current oligomictic regime to persistent thermal stratification during the $21^{\text {st }}$ century, unless reduction of global greenhouse gas (GHG) emissions started immediately.

The 1D model SIMSTRAT (Goudsmit et al., 2002) was used in 5 papers. SIMSTRAT computes vertical transport of heat by vertical turbulent diffusion over a 
Eulerian array of layers, employing a $k-\varepsilon$ turbulence closure (where $k$ is the turbulence kinetic energy and $\varepsilon$ is the dissipation rate of the turbulence kinetic energy). Peeters et al. (2002) calibrated and validated SIMSTRAT over a 50-year period for Lake Zürich, observing that the model could adequately reproduce the vertical thermal structure even under extreme conditions. Straile et al. (2015) modelled the warming of Lake Constance in the past 19792007 period, to investigate the sensitivity of the observed phenology between phytoplankton, Daphnia galeata and whitefish (Coregonus suidteri) to increasing air temperature. They concluded that asynchronous variations in phenology only occur if warming is seasonally heterogeneous and not constant throughout the year. The degree and the direction of such asynchrony depend on the specific seasonality of the warming, so that it is fundamental to have reliable warming predictions at a sub-seasonal resolution. Råman Vinnå et al. (2017) compared SIMSTRAT against the 3D model Delft3D (Lesser et al., 2004), to study the effects of anthropogenic thermal pollution in Lake Biel due to cooling water from a nuclear power plant entering the inflowing River Aare. The effects of such thermal pollution source were also compared to those of ongoing climate change. A river intrusion algorithm, not originally present in SIMSTRAT, was introduced for the purpose, neglecting turbulent entrainment and thus providing a lower limit for the intrusion depth as the level of equal density. The outflowing volume was set equal to the inflowing one, as changes in lake level could not be simulated by the model. Results showed that SIMSTRAT reproduced well the observed temperatures in the epilimnion and hypolimnion, while errors were the largest in the metalimnion, due to baroclinic movements being unresolved by $1 \mathrm{D}$ models. When the model was run without the river intrusion, its performances decreased drastically, highlighting the relevance of inflows for a lake with such a short water residence time (58 days). Gaudard et al. (2019a) presented an open-access web platform to visualise the real-time continuous outputs of the model SIMSTRAT for 54 Swiss basins (among which there are 15 MLDEPLs), for use by environmental and water management agencies. The potential of high-frequency lake model data was illustrated, highlighting the different responses of Swiss lakes. Gaudard et al. (2019b) estimated the potentials for heat extraction and disposal for the main Swiss lakes, detailing the study for Upper Lake Constance and Lower Lake Zürich, for which SIMSTRAT was applied to investigate the effects on the lake thermal structure for different design and operating parameters. They concluded that safe use of lakes as heat sources or sinks led to a general energy availability which is an order of magnitude higher than the maximum regional demand of heating and cooling, potentially allowing a strong reduction in the use of fossil fuels in Switzerland.
Two further studies proposed an own 1D hydrodynamic model. Danis et al. (2004) implemented a model combining the eddy diffusivity model by Henderson-Sellers (1986), the ice model by Patterson and Hamblin (1988) and a water transparency model considering the optical effect of the seasonal algal cycle. They applied it to Lake Annecy and Lake Ammer, calibrating over past observations and performing prognostic continuous simulations for the $21^{\text {st }}$ century. Results projected Lake Annecy to maintain rather regular full overturns, while Lake Ammer would be expected to become meromictic. Vinçon-Leite et al. (2014) instead used a 1D hydrodynamic model of Lake Bourget which had been already implemented in Vinçon-Leite (1991), employing for the eddy diffusivity the model by Simons (1981) in the surface mixed layer and a power function of the BruntVäisalä frequency below. The long-term thermal evolution of Lake Bourget in the period 1976-2008 was simulated, highlighting the importance of numerical models in filling the gaps between discrete water temperature observations.

We last mention in this paragraph the work by Livingstone (2003), in which a heat exchange model with a single layer was employed, i.e., as a matter of fact, a 0D one-box thermodynamic model. Such model was applied to evaluate the warming of Lake Zürich in the period 1947-1998, focusing on the heterogeneous changes that have occurred in surface heat flux balance between night and day, altering the lake thermal structure.

\section{Coupled ecological-hydrodynamic models}

Among the papers dealing with 1D coupled ecological-hydrodynamic models, two works employed as physical driver the General Ocean Turbulence Model (GOTM), which solves the Reynolds-Averaged NavierStokes (RANS) equations with several available options for turbulence closure, coupled to a biogeochemical model through the Framework for Aquatic Biogeochemical Models (FABM) interface. Kerimoglu et al. (2017) studied Lake Bourget and linked GOTM-FABM to an own ecological model including 6 plankton groups identified through allometric relationships (P. rubescens, small and large phytoplankton, mixotrophs, herbivorous and carnivorous zooplankton). The simulation of the 20042010 period led to good estimates of water temperature and dissolved inorganic $\mathrm{P}$ concentration and intermediate ones of plankton succession. Krishna et al. (2021) interfaced GOTM-FABM with the biogeochemical model Ecological ReGional Ocean Model (ERGOM; Neumann et al., 2002), to understand the mechanisms leading to the large differences in primary production rates and nutrient concentrations observed in two consecutive years (20122013) on Lake Geneva. The simulation showed that the exceptionally cold winter in the first year triggered deep 
convection in the lake, resulting in an almost complete overturn. This led to high algal biomass build-up in the productive season due to the abundance of dissolved inorganic $\mathrm{P}$ in the surface layer. On the contrary, in the following year strong P limitation was present, due to weak nutrient replenishment at the end of winter.

Two further studies on Lake Maggiore coupled GLM to the Aquatic EcoDynamics biogeochemical model (AED2; Hipsey et al., 2013). In Fenocchi et al. (2019), the coupled model was calibrated and validated over an almost 17-year-long period, concentrating on the reproduction of deep-water chemistry and of phytoplankton biomass and succession. Even if some simplifications, leading to some limitations for long-term prognoses, were necessary to model such a complex basin, the resulting performances were comparable to those obtained in literature for smaller and shallower lakes over shorter periods. The coupled model was later applied in Fenocchi et al. (2020) to simulate the 2020-2085 physical, chemical and phytoplankton dynamics of Lake Maggiore, considering the CH2011 climate change scenarios and testing increases and decreases in nutrient loads. Results showed that diminishing mixing intensity would lead to hypolimnetic anoxia regardless of a reduction in nutrient input, unless global GHG emissions were immediately reduced. The total phytoplankton biomass instead strongly depends on nutrient input, so that it would weakly be affected by climate change, yet water warming would cause cyanobacteria to dominate over diatoms.

In a further work on Lake Maggiore by Dueri et al. (2009), the 1D version of the finite-difference hydrodynamic model COHERENS (COupled Hydrodynamical Ecological model for REgioNal Shelf seas; Luyten et al., 1999) was coupled to a contaminant fate module (Jurado et al., 2007) to simulate the water column concentrations of polychlorinated biphenyls (PCBs) in the Ispra Bay, considering exchanges with the atmosphere and the sediments.

Three other papers employed fully original 1D coupled ecological-hydrodynamic models. Vinçon-Leite et al. (1995) presented a coupled model of Lake Bourget adopting as state variables water temperature, dissolved mineral $\mathrm{P}$, particulate algal $\mathrm{P}$, particulate zooplankton $\mathrm{P}$ and DO. The coupled model is based on the implementation in Vinçon-Leite (1991), adopted also in Vinçon-Leite et al. (2014). It allowed reproducing the observed partial winter turnovers leading to low hypolimnetic DO levels, triggering the release of orthophosphate $\left(\mathrm{PO}_{4}\right)$ from sediments. Panizzuti and Tartari (1995) used a coupled hydrodynamic-chemical model to simulate the $\mathrm{pH}$ evolution in Lake Orta. The model, named ORTAMOD, is composed of two modules: i) the hydrodynamic-chemical driver ORTALAKE, derived from both the MINLAKE model (Minnesota Lake Water Quality Management Model; Riley and Stefan, 1988), and an early version of the RESQUAL II model (Gulliver and Stefan, 1982); ii) the $\mathrm{pH}$ model pHORTA, based on the work by Chapra and Reckow (1983). ORTAMOD showed good results in the simulation of $\mathrm{pH}$ in Lake Orta in the late 1980s, before liming was performed to reduce acidification (Calderoni and Tartari, 2000). Joehnk and Umlauf (2001) last introduced a 1D model of Lake Ammer coupling a hydrodynamic driver implementing the $k-\varepsilon$ turbulence closure and a DO model. The model yielded good results in reproducing the processes leading to the metalimnetic DO minimum, yet a strong influence of calibration parameters was found, limiting prognostic use.

\section{D models}

\section{Hydrodynamic models}

Papers employing 3D models have seen an exceptional rise in the last 2011-2020 decade, 24 out of 28 of them having been published in this period. The most used models are Delft3D and ELCOM (now AEM3D), employed in 13 and 11 papers, respectively. Delft3D (Lesser et al., 2004) is an open-source code by the Deltares Institute, while ELCOM/AEM3D (Estuary and Lake COmputer Model; Aquatic Ecosystem Model) has been developed by the University of Western Australia (Hodges et al., 2000). Scheu et al. (2018) employed the opensource model SUNTANS (Stanford Unstructured Nonhydrostatic Terrain-following Adaptive Navier-Stokes Simulator) by the Stanford University (Fringer et al., 2006), which solves the RANS equations with the Boussinesq and hydrostatic approximations through a finite-volume approach. Four works instead applied an own solver of the Navier-Stokes equations (Salvadè et al., 1992; Mari et al., 2009; Ambrosetti et al., 2012; Ulloa et al., 2019).

The earliest application of 3D models in the bibliographic corpus is represented by Salvadè et al. (1992), who reported the pioneering $3 \mathrm{D}$ hydrodynamic modelling studies performed on Lake Lugano. Their first own implementation of the Spraggs and Street (1975) model simply solved the 3D hydrostatic RANS equations of mass and momentum conservation for water at constant density and constant wind stress forcing. However, their ensuing own implementation of the Oman (1982) model was already comparable with current $3 \mathrm{D}$ models, solving the $3 \mathrm{D}$ hydrostatic RANS equations of mass, momentum and energy conservation with the Boussinesq approximation for density, reproducing baroclinic motions. This latter model was initialised with an observed vertical temperature profile and boundary conditions were given by multiple inlake stations. Significant limitations were the coarse grid, given the limited computational resources available at the time, the employed finite-difference scheme, leading to strong numerical diffusion, and the rigid lid approximation. In Salvadè et al. (1992), simplified models of surface 
and internal seiches in Lake Lugano were also presented, solving the harmonic linear equations that characterise such motions (Hutter, 1984). The observed oscillations of both the thermocline and the halocline of the North basin were reproduced through a three-layer internal-wave model, while resonances between the three basins were found for surface seiches. The same harmonic equations for internal seiches were coupled in Cuypers et al. (2011) to a passive scalar transport equation, to interpret the observed vertical and horizontal distribution in Lake Bourget of $P$. rubescens, which proliferates in the metalimnion.

The most popular models Delft3D and ELCOM/AEM3D were compared in Dissanayake et al. (2019) for Upper Lake Constance against temperature profiles and current velocity and drifter measurements. Almost equivalent accuracy was found between them for the prediction of stratification, internal seiches and surface currents, Delft3D yet attaining slightly better performances. Differences between the models were smaller than those between models and observations, suggesting that the input meteorological parameters have more impact than the different numerical formulations. Regarding those, Delft3D and ELCOM/AEM3D solve in their standard layouts the RANS equations with the Boussinesq and hydrostatic approximations, Delft3D employing in its main hydrodynamic module Delft3D-FLOW a finite-difference approach with an Alternating Direction Implicit (ADI) scheme (Stelling and Duinmeijer, 2003), while ELCOM/AEM3D adopts a semi-implicit hybrid finitedifference/finite-volume approach based on the TRIM (Tidal, Residual, Intertidal Mudflat) model by Casulli and Cheng (1992). The horizontal components of eddy viscosity and diffusion are parameterised in both models, strongly depending on the mesh resolution, while more accurate closures are used along the vertical. ELCOM/AEM3D uses a mixed-layer approach applied to each vertical stack of cells, derived from the one employed in the 1D DYRESM and GLM models. In Delft3D it is instead possible to choose between fixed vertical eddy viscosity and diffusion values, an algebraic zero-equation model, a $k-L$ one-equation model and a $k$ - $\varepsilon$ two-equation model, the last most advanced option being used in all the reviewed applications.

Automatic calibration techniques have been successfully employed for the application of Delft3D to Lake Geneva in Baracchini et al. (2020), being supported by multi-site temperature profiles and current velocity measurements. However, compromises were made to calibrate water temperature and current velocity independently, simplifying the procedure.

A relevant problem of $3 \mathrm{D}$ model applications is the need for spatially distributed boundary conditions. Among input meteorological variables, wind displays the most definite horizontal patchiness and needs the most spatially and temporally accurate description. In fact, wind inhomogeneities determine the layout of surface currents and of internal waves (Råman Vinnå et al., 2017; Valerio et al., 2017; Amadori et al., 2018). This is especially true for the MLDEPLs, which are surrounded by mountains, leading to strong wind spatial patchiness that adds up to the daily alternating patterns. As single-site measurements are suitable only for small basins, furthermore tending to underestimate on-lake wind stress if done on land (Valerio et al., 2017), and as networks of in-lake wind stations to build spatially interpolated fields have been successfully operated up to now only for limited time inside research projects, as done for few years on Lake Como (Morillo et al., 2009; Laborde et al., 2010, 2012; Copetti et al., 2020) and Lake Iseo (Vilhena et al., 2013; Valerio et al., 2017), the most solid solution to solve wind inhomogeneities are atmospheric models. Works on Swiss lakes have employed the hourly reanalysis data from the MeteoSwiss atmospheric model COSMO (Consortium for Small-Scale Modeling; www.cosmo-model.org), both through its older version COSMO-2 (Bonvin et al., 2013; Razmi et al., 2013, 2014; Råman Vinnå et al., 2017, 2020; Soulignac et al., 2018; Dissanayake et al., 2019; Nouchi et al., 2019; Baracchini et al., 2020; Caramatti et al., 2020) and through the new one COSMO-1 (Baracchini et al., 2020; Caramatti et al., 2020). While COSMO-2 has $2.2 \mathrm{~km}$ resolution and data can be retrieved since 2008, COSMO-1 has $1.1 \mathrm{~km}$ resolution, data being available from 2016 onwards. These reanalysis products are obtained initialising COSMO every hour with variable fields obtained combining the results from the previous model run with observations (Caramatti et al., 2020). Recent works on Lake Garda (Amadori et al., 2018, 2020; Piccolroaz et al., 2019) and on Lake Iseo (Valerio et al., 2017) instead produced their own distributed meteorological data through the model WRF (Weather Research and Forecasting; Skamarock and Klemp, 2008). This allowed tailoring meteorological data at higher resolutions than COSMO, both in space $(0.25 \mathrm{~km}$ resolution in Valerio et al., 2017) and time (15 min resolution in Amadori et al., 2018, 2020). Valerio et al. (2017) compared the representation of the internal wave field given by ELCOM simulations forced with meteorological data produced with WRF against those obtained with COSMO-2 data provided by the Regional Environmental Protection Agency of Emilia-Romagna (ARPAE). They found that the $2.2 \mathrm{~km}$ resolution of the COSMO-2 data leads to an underestimation of oscillatory motions for a lake of the size of Lake Iseo (65.3 $\mathrm{km}^{2}$; Tab. 2) surrounded by complex orography. However, use of WRF requires higher computational resources than the $3 \mathrm{D}$ hydrodynamic model, in addition to expertise in computational atmospheric physics to be properly set up.

In all the reviewed papers dealing with $3 \mathrm{D}$ models, the initial conditions were defined setting a single surveyed 
vertical temperature profile throughout the lake volume and assuming water-at-rest conditions for current velocities. A spin-up period is hence required for internal waves and surface currents to develop in the model, spanning from 2 days (Valerio et al., 2017; Amadori et al., 2018; Piccolroaz et al., 2019) to 25 days (Razmi et al., 2013, 2014). Model spin-up protracts computational times with a dummy early part of the simulation and introduces some approximation, as slow hypolimnetic currents and internal waves in deep lakes have components which result from past motions over time scales longer than the spin-up period. However, appointment of initial conditions in 3D models cannot be sensibly improved, apart from using multiple simultaneous observed vertical temperature profiles to start from an already-deformed thermocline, such measurements yet hardly ever being available.

Distributed data are also needed for the calibration and validation of $3 \mathrm{D}$ models, as ordinary lake monitoring performed by periodic sampling at single or few sites per lake is not enough to assess spatial and small-scale temporal variations. As operating networks of in-lake monitoring stations is still problematic, data inferred from satellite images would strongly be beneficial (Soulignac et al., 2018; Nouchi et al., 2019; Baracchini et al., 2020), providing maps of variables such as surface temperature, turbidity and Chl- $a$ for a whole lake at intervals of few days. Yet, winter fog and clouds may be an operative problem for some perialpine lakes (Caramatti et al., 2020). Satellite images can also be used together with hydrodynamic models to investigate on the inference of hydrodynamics on biochemical processes, this solution being less demanding than implementing a 3D coupled ecological-hydrodynamic model. On this subject, Soulignac et al. (2018) employed Delft3D to understand the hydrodynamic mechanisms leading to the spatial and temporal patchiness of phytoplankton in Lake Geneva observed from satellite images. Nouchi et al. (2019) instead combined Delft3D simulations with remote-sensed images and field samples to investigate on whiting events taking place in Lake Geneva, proving that calcite $\left(\mathrm{CaCO}_{3}\right)$ precipitation was indeed the cause and finding that the inflowing River Rhône provided the suspended sediments that trigger the process.

Still on the use of indirect field data to support 3D hydrodynamic modelling, Scheu et al. (2018) used sediment traps and cores to aid simulations performed with SUNTANS aimed at determining the paths of suspended sediments released by River Toce into Lake Maggiore. A similar approach combining data from traps and cores with Delft3D simulations was followed by Råman Vinnå et al. (2020), to identify areas prone to subaquatic landslides in Lake Biel due to the intrusion of sediment-laden River Aare. Underflow dynamics of sediment-laden plumes were also studied for the intrusion of River Rhine into Upper Lake Constance by Mirbach and Lang (2018), who aimed through ELCOM simulations at determining the influence of plunging riverine water and entrained epilimnetic water on deep-water renewal.

Investigations on lake hydrodynamics through 3D modelling can also benefit from information obtained from public interviews to experienced lake users, i.e., through a citizen science approach. Local knowledge can be used both to validate models, especially as regards surface currents, which would otherwise require extensive field measurements, and to discover specific phenomena to analyse through numerical simulations. In Laborde et al. (2012), numerical modelling confirmed knowledge on the surface currents and internal waves of Lake Como gained from local fishermen, their nets being ordinarily displaced by these processes. Amadori et al. (2020) extended the interviews to recreational lake users, ferry boat drivers, firefighters and officers of the local environmental protection agency to get a picture of surface currents in Lake Garda. Caramatti et al. (2020) used data from newspapers, blogs and social media to supplement governmental information on ice cover in Lower Lake Constance, to validate the results on the reproduction of its annual development obtained from simulations with AEM3D integrated by the Oveisy et al. (2012) ice model.

In the comparison between 1D SIMSTRAT and 3D Delft 3D performed in Råman Vinnå et al. (2017) on Lake Biel, it was found that the system-wide effects of thermal pollution from River Aare on the vertical thermal structure were identified by both models. However, the extreme local epilimnetic temperature variations, which are needed to estimate the risks for the biota, were identifiable only with Delft3D, which also performed much better in the metalimnion, as it solves the movements of the thermocline. The 3D model further allowed following the path of River Aare inside Lake Biel from the inlet to the outlet, disentangling its interactions with lake circulations and thermal stratification.

Three-dimensional models allowed understanding the relevance of geostrophic effects for the elongated Italian MLDEPLs Lake Maggiore, Lake Iseo, Lake Como and Lake Garda. Deviations in the paths of the plumes of the tributaries were highlighted on Lake Maggiore by Ambrosetti et al. (2012), who simulated through an own 3D solver the paths of Lagrangian markers to infer the residence time of lake water, and by Scheu et al. (2018). Pilotti et al. (2014b) employed a rotating physical model of the northern portion of Lake Iseo to study the deflection operated by the Coriolis force on the entrance of the two main tributaries, River Oglio and the Canale Industriale. The results of the scale model were supported by both 3D simulations with ELCOM and field data. For Lake Como, numerical ELCOM investigations supported by field measurements in Laborde et al. (2010) and Copetti et al. 
(2020) stressed how geostrophic effects deviate the cleanwater plumes of the main northern inflows River Adda and River Mera towards the western shore, driving them into the polluted southwestern Como arm. Such beneficial water exchange is further empowered by the main $\mathrm{V} 1 \mathrm{H} 1$ and $\mathrm{V} 2 \mathrm{H} 1$ internal wave modes, which displace water between the northern and southwestern arms (Guyennon et $a l ., 2014)$, thus alleviating the nutrient and Chl- $a$ gradients in the lake. The support of downward-pointing impellers to these natural mitigation processes occurring in Lake Como was explored in Morillo et al. (2009), in which ELCOM numerical simulations were validated through field dye experiments on a pilot impeller. Amadori et al. (2018) and especially Piccolroaz et al. (2019) underlined through Delft3D simulations supported by field measurements how planetary rotation drives secondary currents in the narrow, deep and steep northern basin of Lake Garda under winter conditions with Föhn winds aligned with the lake structure. These currents make warmer surface water plunge downwards at the western shore, being replaced at the eastern shore by upwelled colder deep water, thus providing deep ventilation.

As a last remark, the computationally efficient hydrostatic approximation, which is suitable for the typical slow vertical motions of lakes and the commonly employed coarse grids (Dissanayake et al., 2019), is used in all the reviewed applications of 3D models, except for two works in which non-hydrostatic effects are explicitly addressed. Vilhena et al. (2013) compared the hydrostatic and non-hydrostatic (Wadzuk and Hodges, 2009) versions of ELCOM against field observations for Lake Iseo, focusing on non-linear internal waves. They found out that after storm events a relevant amount of lake energy is moved from basin-scale low-frequency linear internal waves to small-scale high-frequency non-linear ones. The dissipation processes of these non-linear waves are intrinsically non-hydrostatic and are balanced by numerical diffusion in hydrostatic models. In Ulloa et al. (2019), the RANS simplification adopted in all the other 3D papers was removed together with the hydrostatic approximation, performing a numerical experiment with an own Large Eddy Simulation (LES) non-hydrostatic solver on an ideal trapezoidal prismatic basin shaped after the Lake Alpnach basin of Lake Lucerne. Such simplified LES model allowed gaining an insight on Benthic Boundary Layer (BBL) currents not possible with RANS models. In fact, the RANS scheme fails at small scales, especially near the bottom, as the logarithmic wall law assumed in RANS models does not hold for baroclinic motions. Three-dimensional RANS models should further include modified turbulence models to account for the effects of stratification on the turbulence field, as done by SUNTANS, in which the Canuto-A stability function (Canuto et al., 2001) is used to parameterise the effects of stratification on vertical mixing in the Mellor-Yamada level 2.5 turbulence model (MY2.5; Mellor and Yamada, 1982) used to compute vertical eddy viscosity and diffusivity, horizontal components being parameterised (Scheu et al., 2018). In LES, energetically relevant turbulence is directly solved, thus including the effects of stratification.

\section{Coupled ecological-hydrodynamic models}

Only 2 works among the 28 papers dealing with 3D models employ coupled ecological-hydrodynamic models. In both cases, the hydrodynamic drivers are not coupled to complete biogeochemical modules reproducing nutrient cycles aimed at ecosystem modelling, as common in 1D applications. In Mari et al. (2009), an own hydrodynamic model based on a volume-conservative finite-element approach, solving the hydrostatic Boussinesq RANS equations, was coupled to a population dynamics model without any chemical and biological background, to reproduce Lagrangian larval transport and sessile adult-stage reproduction of an ideal species in Lake Garda. In Bonvin et al. (2013), the Delft3D model of Lake Geneva developed in Razmi et al. $(2013,2014)$, there used to assess the hydrodynamics and residence time in the Vidy Bay under different conditions, was coupled with an own photolysis model. The study aimed at assessing micropollutant contamination risk for the local drinking water intake from a wastewater outfall (see Saha et al. (2011) for a work over the same subject in Upper Lake Constance, employing hydrodynamic ELCOM simulations; see also Schwefel et al. (2018), in which the Razmi et al. $(2013,2014)$ Delft3D hydrodynamic model of Lake Geneva was applied to infer the representativeness of the hydrodynamic conditions experienced during a field campaign).

\section{OD ecological-only models}

Twenty papers inside the bibliographic corpus adopted $0 \mathrm{D}$ ecological-only models. Phosphorus budget models are the most represented, with 6 works. Rossi et al. (1986) applied a model with three vertical box interactive layers to a bay of Lake Lugano. The description of the P cycle included dissolved inorganic, dissolved and particulate organic $\mathrm{P}$ and their transformation into the inorganic dissolved form. The model was used to evaluate the mean $\mathrm{P}$ residence time in the lake compartments and the total phosphorus (TP) turnover time in the ecosystem, in addition to estimate the $\mathrm{P}$ abatement in the lake in response to input load reductions. Schauser et al. (2004) presented the SPIEL (Sedimentary Phosphorus In Eutrophic Lakes) model, aiming at simulating the diagenesis of $\mathrm{P}$ within the sediments of eutrophic lakes. SPIEL is structured in modules, in-lake restoration interventions such as oxidation with DO or nitrate, precipitation with iron or aluminium, 
sediment capping and hypolimnetic withdrawal being reproducible by activating a specific module for each of them. The model was calibrated and validated for Lake Sempach, for which a sensitivity analysis of SPIEL was later presented in Schauser et al. (2006). Bryhn et al. (2010) developed and tested the dynamic model MeroLakeMab on Lake Bourget, with the purposes of reconstructing the $\mathrm{P}$ loading history and forecasting TP concentrations under different climatic and hydrological scenarios. Simulations suggested that: (1) TP load decreased by about $88 \%$ between the early 1980 s and the late 1990s; (2) the effects of future temperature warming on the yearly mean TP concentrations would be small compared to the effects of changes in the TP load; (3) future decrease in the lake inflow discharge would not affect TP concentrations markedly. Müller et al. (2014) examined data from the monitoring of 4 eutrophic Swiss lakes (including the MLDEPLs Lake Hallwil and Lake Sempach) which have undergone re-oligotrophication in the last 25 years, revealing that both net sedimentation rates and export rates of $\mathrm{P}$ increased as the in-lake concentrations decreased. These findings highlighted that the $\mathrm{P}$ concentration in eutrophic lakes could in some cases decrease more than linearly with a reduction in external load, i.e., faster than predicted by the applied traditional Vollenweider (1975) eutrophic-statebased model. Lepori and Roberts (2017) used a model derived from Nürnberg (1998) and investigated how reductions in external $\mathrm{P}$ load triggered a decline in Lake Lugano P and Chl- $a$ concentrations. During the 1983-2014 study period, nutrient management within the watershed approximately halved external $\mathrm{P}$ load, yet the responses of in-lake $\mathrm{P}$ and $\mathrm{Chl}-a$ concentrations also reflected variations in internal load and food-web structure.

Omlin et al. (2001a, 2001b) introduced the processbased model BELAMO (Biogeochemical and Ecological LAke MOdel), developed for Lake Zürich and implemented inside the AQUASIM framework (Reichert, 1994). In the first work, a preliminary sensitivity analysis on model parameter identification was performed. Plankton growth parameters were found to be the most difficult to be properly identified, while those linked to the dynamics of dissolved chemical variables could be much more easily defined. In Omlin et al. (2001b), the structure of BELAMO is first described. The model calculates horizontally averaged substance and organism concentrations along the stratified water column, these being shaped by a parameterised vertical mixing, making use of fixed vertical diffusion coefficients. Sedimentation, inflows, outflows and biogeochemical processes at the sediment-water interface are included. The chemical module reproduces the DO, $\mathrm{P}$ and $\mathrm{N}$ cycles, whereas the biological one includes the dominant species $P$. rubescens, a generic phytoplankton group and an herbivore zooplankton group. The calibrated model was able to reproduce key features of nutrient and DO vertical profiles and of phytoplankton-zooplankton interactions in Lake Zürich over several years, but not to predict occasional blooms. Dietzel and Reichert (2012) further used BELAMO as case-model to study the generation and propagation of systematic errors in complex deterministic models, using the long-term input data from Lake Zürich.

Two other works deal with statistical approaches to simulate and predict phytoplankton dynamics, focusing on the proliferation of potentially toxic cyanobacteria species. Gallina et al. (2017) studied the impact of climate change on P. rubescens in Lake Geneva. Extreme hot air temperature events were used as a proxy of future climate and Multi-Adaptive Regression Splines (MARS) were adopted to model and predict future changes in $P$. rubescens biomass. The outcomes suggested a strong increase in the concentrations of this cyanobacterium, air temperature warming leading to high spring inoculum concentrations, thus triggering an outbreak during the summer. Derot et al. (2020) instead adopted machinelearning (ML) techniques as an alternative to processbased models to reproduce the development of harmful algae. Predictions were performed pairing two ML models with a long-term learning database of algal blooms spanning 34 years.

Primary production is modelled without any chemical background in two further papers. Finger et al. (2013) analysed 28 years of ${ }^{14} \mathrm{C}$ assimilation rates, as well as other biotic and abiotic parameters, such as global radiation, nutrient concentrations and plankton densities in Lake Lucerne, to determine the effects of re-oligotrophication on primary productivity. They used a simple model implementing a productivity-light relation, through which they estimated a continuous series of primary production, interpolating the gaps between field observations. The uncertainty of the model was assessed through Monte Carlo simulations. Results underlined that nutrient management within the watershed has successfully improved water quality. However, while nutrient concentrations have decreased by more than an order of magnitude, primary production has decreased only slightly, varying significantly from year to year due to meteorological conditions. Franchini et al. (2017) proposed an improvement to existing mathematical interpolation models that calculate cumulative (i.e., seasonal or annual) primary production rates from instantaneous (i.e., hourly) sampled production values. This was performed employing photosynthetic parameters estimated from solar irradiance and TP-adapting equations previously used in marine studies. The algorithms were calibrated and validated through the 19832014 series of primary production measured in Lake Lugano.

Two other papers relate with food-web models. Both studies deal with Lake Annecy and used models imple- 
mented inside the Ecopath with Ecosim framework (Christensen et al., 1992). Janjua and Gerdeaux (2009) studied trophic interactions in Lake Annecy using 14 food-web functional groups. The resulting food-web parameters showed that Lake Annecy is a mature and relatively stable ecosystem. Lemaire et al. (2020) improved the model of Janjua and Gerdeaux (2009) to assess potential impacts of strong variations in young-of-the-year (YOY) perch biomass on the food web. The results indicated that strong variabilities in the abundance of YOY perch had little effects on the main food-web flows and pathways because of the capacity of the predators to feed on different prey, yet they could induce significant variations in the food-web properties and organisation.

The remaining contributions employing ecologicalonly models cannot be grouped together. Baudo (2002) attempted to fit the history of pollution and recovery of Lake Orta to the ecological theory of resilience. The Lake Orta ecosystem was perturbed by the onset of pollution in the 1920s, settling in another stable state characterized by very low water $\mathrm{pH}$ (Panizzuti and Tartari, 1995). A folded surface scheme reveals that after a restoring event, such as the liming of the whole lake (Calderoni and Tartari, 2000), an ecosystem would not merely revert its pathway, but it would evolve in a similar (but never completely identical) to completely different way, showing hysteresis. The observed variations of phytoplankton, zooplankton, benthos and fish in Lake Orta were further investigated applying a stochastic exponential population growth model. Enz et al. (2002) used a population dynamics model, implemented inside the STELLA framework (Costanza et al., 1998), to evaluate mortality factors for whitefish in Lake Hallwil. They used as input variables the number of whitefish larvae stocked annually and the mean age of gillnetted whitefish, while data on annual whitefish yield and year-class strength (YCS) were used for model validation. Results showed that warmer and sunnier weather conditions in May negatively influenced whitefish yield and YCS, likely because gas supersaturation resulting from intense DO production by algae during warm sunny weather causes lethal-gas-bubble syndrome in whitefish larvae. Buerge et al. (2003) presented a study in which caffeine was used as a chemical marker for water surface pollution by domestic wastewaters in Lake Greifen (Switzerland) and MLDEPL Lake Zürich. They carried out systematic caffeine measurements in the influents and effluents of wastewater treatment plants (WWTPs) and in lake surface waters. A model reproducing caffeine concentrations, including the processes of flushing, biodegradation and indirect photodegradation by reaction with $\mathrm{HO}$ radicals was implemented inside the AQUASIM framework (Reichert, 1994). Vertical mixing was described by time- and depth-dependent turbulent diffusivity coefficients, estimated with the heat budget method from monthly temperature profiles. Their results showed that WWTPs efficiently reduced caffeine concentrations by $81-99.9 \%$. Moschet et al. (2013) carried out a study in Lake Constance aimed at evaluating the exposure to micropollutants (MPs) from a large catchment. After an in-depth field analysis and a modelling exercise of the input loads of MPs from the watershed, they applied the MASAS substance budget model (Ulrich et al., 1995) to predict the long-term trends of in-lake concentrations. The model considers the flushing of the lake, the water exchanges between epilimnion and hypolimnion and the direct photolytic degradation. A comparison of MASAS predictions with lake measurements showed good results for almost all MPs. Possible mitigation options were also evaluated, a post-ozonation step upgrade in the major WWTPs leading to significant reductions in the input loads of MPs. Finally, Minella et al. (2016) calculated the steady-state concentrations of photoinduced transient chemical species in Lake Garda, Lake Geneva and Lake Iseo through the APEX (Aqueous Photochemistry of Environmentally occurring Xenobiotics) photochemical model (Bodrato and Vione, 2014). Alterations in water chemistry due to climate change are expected to produce very heterogeneous photochemistry patterns among the studied lakes, depending on changes in dissolved organic $\mathrm{C}$ concentrations and water alkalinity.

\section{DISCUSSION}

The exponential increase in time of modelling studies of the MLDEPLs evident from the reviewed bibliographic corpus suggests a growing interest in quantitative approaches forecasting the outcomes of management actions and climate change. Such growth has been supported by the constant improvement of computational resources, allowing more complicated problems and environments to be modelled and more scenarios to be considered, thus raising the potentialities of modelling tools. German and Austrian MLDEPLs other than Lake Constance and Lake Ammer are not dealt within the reviewed bibliographic corpus, so that future modelling investigations to expand the available knowledge on them represent a priority.

The recent outbreak of papers employing 3D models has been allowed by their execution now being possible in ordinary workstation computers. At the same time, 3D models can solve the spatial heterogeneities of the limnological processes occurring in large deep lakes, in which rapidly displacing surface phytoplankton patches are common (Kiefer et al., 2015), in response to wind-driven currents and the spatial heterogeneity of environmental conditions (Huang et al., 2014; Cyr, 2017). This is especially relevant in multi-basin lakes (Salvadè et al., 1992; Copetti et al., 2020). These phenomena are potentially fully represented by $3 \mathrm{D}$ coupled ecological-hydrodynamic 
models employing a complete ecosystem module. Yet, their application has been to date made difficult, to the point that the reviewed bibliographic corpus does not include any work in which they are employed, while several examples exist with 1D hydrodynamic drivers. Complete ecosystem modules nevertheless already exist for the most used models Delft3D (Delft3D-ECO module; Los et al., 2008) and ELCOM/AEM3D (CAEDYM module - Computational Aquatic Ecosystem DYnamics Model; Hamilton and Schladow, 1997).

A first obstacle to the use of 3D coupled complete ecological-hydrodynamic models lies in model calibration. In fact, the computational times needed to perform 3D simulations are not yet small enough to realistically allow performing manifold preliminary runs for parameter optimisation, as is instead possible with 1D models, at least for commonly available workstation computers. Huge reductions in computational times could be obtained if model execution were moved from the computer processor (CPU - Central Processing Unit) towards the graphics card (GPU - Graphics Processing Unit), allowing in ordinary computers an extensive parallelisation of the numerical code which is otherwise possible only in HPC (High Performance Computing) cluster units. At the moment, it seems that the Deltares Institute is moving the first steps towards the GPU implementation of Delft3D (Buwalda, 2020). The computational constraint is especially relevant for $3 \mathrm{D}$ coupled complete models, as huge non-linear, highly site-specific parameter spaces with multiple levels are included in the biogeochemical modules, requiring a multitude of preliminary simulations for calibration. With such complicated parameter interdependencies, automatic calibration techniques can hardly be applied despite their constant improvement, as the problems which Baracchini et al. (2020) highlighted calibrating automatically a 3D hydrodynamic-only model with mutually dependent water temperature and current velocity fields would enormously amplify. Trial-and-error timeconsuming expert-knowledge manual calibration may then be the only option, being already tiresome for coupled 1D models (Fenocchi et al., 2019). Considerable calibration difficulties were in fact reported in a sample application of ELCOM-CAEDYM to the $5.25 \mathrm{~km}^{2}$-wide Italian perialpine Lake Pusiano (Carraro et al., 2012).

Moreover, long-term observed series of a high number of chemical and biological variables should be provided for accurate calibration and validation of coupled complete ecological-hydrodynamic models, being them of 1D or 3D nature. To evaluate the continuous response of models, which allows reproducing short-term physical and biochemical phenomena, data should also be available at high frequency, i.e. at a daily to hourly interval. Even if the long limnological tradition characterising the perialpine region guarantees the existence of some of the longest series of limnological data for some MLDEPLs, such as Lake Maggiore (Fenocchi et al., 2019), available data from periodic sampling are often limited to single locations and to on average monthly frequencies. As such, they are not sufficient for the complete calibration and validation of 1D models on the temporal side and of 3D models on both the temporal and spatial side. Installation of networks of high-frequency monitoring buoys to be eventually managed by the local environmental protection agencies rather than depending on research projects alone has been recently started on Lake Como, Lake Lugano and Lake Maggiore inside the SIMILE Interreg project (Tiberti et al., 2021). Ongoing difficulties in buoy maintenance and data management were highlighted. Most of these problems are not present in the floating laboratory LéXPLORE platform installed on Lake Geneva (Wüest et al., 2021), which allows complete on-site maintenance and control of monitoring sensors, in addition to countless additional research possibilities compared to the use of buoys, yet with much higher costs and a greater visual impact. Use of satellite images could then provide a relevant low-cost help (Pinardi et al., 2015), even if not all the needed environmental variables can be retrieved, subsequent images are spaced apart by few days and only the surface photic layer is represented, leaving out the metalimnion and hypolimnion. Still on the issue of distributed data, obtaining high-resolution wind fields to feed 3D models, which is vital to obtain realistic surface current and internal wave fields (Råman Vinnå et al., 2017; Valerio et al., 2017; Amadori et al., 2018), has only recently been made possible for the MLDEPLs thanks to the use of small-scale meteorological models such as COSMO (www.cosmo-model.org) and WRF (Skamarock and Klemp, 2008).

The same high number of fixed parameters employed by complete ecological modules represents a further problem, as it induces stationarity (Trolle et al., 2008a, 2008b). This limits the applicability to future projections, as variations in the species aggregates and thus in the ecological succession cannot be simulated (Burger et al., 2008; Fenocchi et al., 2019, 2020). In this regard, advanced statistical modelling approaches involving ML techniques do not offer any advantage over process-based models for long-term prognoses, while providing good results for short-term studies (Gallina et al., 2017; Derot et al., 2020). In fact, their base is purely parametrical and machine-knowledge on the processes driving the evolving ecosystem is not available to the models (Vinçon-Leite and Casenave, 2019).

In principle, coupling a hydrodynamic model to an ecosystem module reproducing primary production can improve the accuracy of hydrodynamic simulations themselves (Hamilton and Schladow, 1997). In fact, a time-dynamic estimation of the light extinction coefficient as function of algal population and particulate substance 
concentration can be straightforwardly passed to the hydrodynamic driver (Rinke et al., 2010), as done for example in GLM-AED2 (Hipsey et al., 2013). Still on the links between the biogeochemical module and the hydrodynamic driver, a relevant shortcoming of coupled 1D and $3 \mathrm{D}$ ecological-hydrodynamic models is the missing capability to reproduce the precipitation of $\mathrm{CaCO}_{3}$, a frequent phenomenon in the MLDEPLs (Nouchi et al., 2009). As a matter of fact, to the knowledge of the Authors, all available models represent solutes in the water column through a single salinity conservative variable. Calcite precipitation can be triggered by phytoplankton blooms occurring under heatwaves providing the nucleation cells and is thus expected to occur more frequently in the future. This phenomenon leads to a further stabilisation of the water column in addition to that predicted by available models, as salinity is effectively transferred to the already denser hypolimnion, accelerating the transition towards meromixis (Salmaso et al., 2003). The implementation of calcite precipitation in numerical models should take into account both the occurrence of $\mathrm{CaCO}_{3}$ supersaturation and of the triggering event, which could be of various nature (Nouchi et al., 2019), the two not being contemporaneous (Koschel et al., 1983).

Even if 1D models have proved themselves able to reproduce the mixing dynamics of lakes over broad ranges in latitude, climatic zones and morphometric properties (Bruce et al., 2018), their application to large deep lakes will always seem a bit of a stretch, as both practical and theoretical considerations would push towards the use of $3 \mathrm{D}$ models. An example is the missing reproduction of internal waves, the main kinetic energy source in deep inland waters, whose effects are at best parameterised, as done by GLM (Hipsey et al., 2019) and SIMSTRAT (Goudsmit et al., 2002), which leads to largest errors occurring in the metalimnion (Råman Vinnå et al., 2017). However, the 1D approach still represents a viable compromise between the representation of physics and the computational load for ordinary workstation computers, and as such it has been applied in several studies performing long-term prognostic simulations on the MLDEPLs. Notably, 1D models have proved themselves able to reproduce the oligomictic thermal regime of most of the MLDEPLs, in which full overturns occur only after cold and windy winters (Ambrosetti and Barbanti, 1999), allowing the simulation of their evolution towards meromixis with climate warming (Valerio et al., 2015; Fenocchi et al., 2018). When undertaking these long-term simulations on oligomictic basins, it is essential to perform continuous runs from the present day to the future (Valerio et al., 2015; Fenocchi et al., 2018, 2020) and not reproduce isolated future periods, at worst simulating each year separately. In fact, while the latter approach could be used for dimictic lakes, in which every year the vertical temperature profile is reset twice when the water column passes through the $4{ }^{\circ} \mathrm{C}$ isotherm of maximum density, for oligomictic lakes it would lead to neglecting the annual carryover of heat stored in the hypolimnion between full turnovers. The casual occurrence of the latters also makes relying on single runs to assess the future evolution of the thermal structure insufficient, the statistical analysis of manifold realisations with random meteorological data series allowing a much more solid understanding of the possible outcomes (Fenocchi et al., 2018, 2020).

Among papers employing 0D ecological-only models, the strong presence of models focusing on the P budget should be pointed out. This high attention is due to the role played by this nutrient in limiting algal growth and thus governing productivity. Large interest has also been devoted to the proliferation of $P$. rubescens, which in recent years has increasingly dominated the phytoplankton assemblage of many MLDEPLs. As a matter of fact, the occurrence of blooms of harmful cyanobacteria is of prime importance for risk assessment and management, as it affects the use of lakes for drinking and recreational purposes (Ibelings et al., 2003).

Last, local knowledge has proven itself a promising support to lake modelling activities in the MLDEPLs, providing an experienced perspective on processes occurring in complex natural systems (Laborde et al., 2012; Amadori et al., 2020; Caramatti et al., 2020).

\section{CONCLUSIONS}

This review paper has revealed a growing interest in modelling approaches to understand the functioning and evolution and support the management of the MLDEPLs. Studies applying 3D hydrodynamic models have seen an exceptional rise in the last decade, echoing the curiosity on the physical causes triggering the biochemical heterogeneities observed in the MLDEPLs, especially in multibasin ones. However, coupling of 3D hydrodynamic drivers with ecological modules directly reproducing the patchiness phenomena is still hampered by: i) difficulties in obtaining multi-station ecological datasets with adequate temporal frequency for model calibration and validation; ii) computational times not being yet small enough to perform the manifold runs needed for accurate calibration. Several applications of 1D coupled ecological-hydrodynamic models to long-term forecasts of the impacts of climate change and of management actions on both lake physics and ecology have instead already been published, aided by the low computational burden and relative ease of use of 1D models. Ecological-only models, neglecting the underlying physics, have inferior predictive power, as they are parameterised to work under physical conditions close to the calibration ones, yet they can provide rapid and usually effective answers for watershed managers. 
Future improvements in computational power and optimisation, in the understanding of ecosystem processes, leading to a reduction in model parameterisation, and in automatic calibration techniques are expected to bring about further ease of application and improved performances for 3D coupled ecological-hydrodynamic models. The combination of numerical modelling with remote sensing, in addition to high-resolution in-situ monitoring performed through permanent stations rather than limited to the ordinary periodic sampling, could lead to important improvements in 3D model calibration and validation, especially as regards the reproduction of algal blooms. Nevertheless, this integrated approach needs multidisciplinary contributions to be carried out effectively. The combination of such methods would allow scientists to fill the shortcomings of individual fields, to gain an integrated knowledge of the MLDEPLs.

\section{ACKNOWLEDGMENTS}

The graphical abstract of this paper was created with the free web service WordClouds.com by Zygomatic, which we gratefully acknowledge. We thank two anonymous Reviewers for their insightful comments and suggestions on the manuscript.

\section{REFERENCES}

Amadori M, Morini G, Piccolroaz S, Toffolon M, 2020. Involving citizens in hydrodynamic research: A combined local knowledge - numerical experiment on Lake Garda, Italy. Sci. Total Environ. 722:137720.

Amadori M, Piccolroaz S, Giovannini L, Zardi D, Toffolon M, 2018. Wind variability and Earth's rotation as drivers of transport in a deep, elongated subalpine lake: The case of Lake Garda. J. Limnol. 77:505-521.

Ambrosetti W, Barbanti L, 1999. Deep water warming in lakes: an indicator of climatic change. J. Limnol. 58:1-9.

Ambrosetti W, Barbanti L, Rolla A, Castellano L, Sala N, 2012. Hydraulic paths and estimation of the real residence time of the water in Lago Maggiore (N. Italy): application of massless markers transported in 3D motion fields. J. Limnol. 71:23-33.

Anneville O, Gammeter S, Straile D, 2005. Phosphorus decrease and climate variability: mediators of synchrony in phytoplankton changes among European peri-alpine lakes. Freshwater Biol. 50:1731-1746.

Anneville O, Souissi S, Gammeter S, Straile D, 2004. Seasonal and inter-annual scales of variability in phytoplankton assemblages: comparison of phytoplankton dynamics in three peri-alpine lakes over a period of 28 years. Freshwater Biol. 49:98-115.

Baracchini T, Hummel S, Verlaan M, Cimatoribus A, Wüest A, Bouffard D, 2020. An automated calibration framework and open source tools for 3D lake hydrodynamic models. Environ. Modell. Softw. 134:104787.
Barontini S, Grossi G, Kouwen N, Maran S, Scaroni P, Ranzi $\mathrm{R}, 2009$. Impacts of climate change scenarios on runoff regimes in the southern Alps. Hydrol. Earth Syst. Sci. Discuss. 6:3089-3141.

Baudo R, 2002. Pollution and recovery of Lake Orta (Italy): Resilience at work? Aquat. Ecosyst. Health 5:71-78.

Bodrato M, Vione D, 2014. APEX (Aqueous Photochemistry of Environmentally occurring Xenobiotics): a free software tool to predict the kinetics of photochemical processes in surface waters. Environ. Sci. Proc. Imp. 16:732-740.

Bonvin F, Razmi AM, Barry DA, Kohn T, 2013. Micropollutant dynamics in Vidy Bay - A coupled hydrodynamic-photolysis model to assess the spatial extent of ecotoxicological risk. Environ. Sci. Technol. 47:9207-9216.

Bresciani M, Cazzaniga I, Austoni M, Sforzi T, Buzzi F, Morabito G, Giardino C, 2018. Mapping phytoplankton blooms in deep subalpine lakes from Sentinel-2A and Landsat-8. Hydrobiologia 824:197-214.

Bruce LC, Frassl MA, Arhonditsis GB, et al., 2018. A multi-lake comparative analysis of the General Lake Model (GLM): Stress-testing across a global observatory network. Environ. Modell. Softw. 102:274-291.

Bryhn AC, Girel C, Paolini G, Jacquet S, 2010. Predicting future effects from nutrient abatement and climate change on phosphorus concentrations in Lake Bourget, France. Ecol. Model. 221:1440-1450.

Bueche T, Hamilton DP, Vetter M, 2017. Using the General Lake Model (GLM) to simulate water temperatures and ice cover of a medium-sized lake: a case study of Lake Ammersee, Germany. Environ. Earth Sci. 76:461.

Bueche T, Vetter M, 2014a. Influence of groundwater inflow on water temperature simulations of Lake Ammersee using a one-dimensional hydrodynamic lake model. Erdkunde 68:19-31.

Bueche T, Vetter M, 2014b. Simulating water temperatures and stratification of a pre-alpine lake with a hydrodynamic model: calibration and sensitivity analysis of climatic input parameters. Hydrol. Process. 28:1450-1464.

Bueche T, Vetter M, 2015. Future alterations of thermal characteristics in a medium-sized lake simulated by coupling a regional climate model with a lake model. Clim. Dyn. 44:371-384.

Bueche T, Wenk M, Poschlod B, Giadrossich F, Pirastru M, Vetter M, 2020. GlmGUI v1.0: an R-based graphical user interface and toolbox for GLM (General Lake Model) simulations. Geoscientific Model Dev. 13:565-580.

Buerge IJ, Poiger T, Müller MD, Buser H-R, 2003. Caffeine, an anthropogenic marker for wastewater contamination of surface waters. Environ. Sci. Technol. 37:691-700.

Burger DF, Hamilton DP, Pilditch CA, 2008. Modelling the relative importance of internal and external nutrient loads on water column nutrient concentrations and phytoplankton biomass in a shallow polymictic lake. Ecol. Model. 211: 411-423.

Buwalda F, 2020. Suitability of shallow water solving methods for GPU acceleration. M.Sc. Thesis in Applied Mathematics, Delft University of Technology, Delft, Netherlands: $146 \mathrm{pp}$.

Calderoni A, Tartari GA, 2000. Evolution of the water chemistry of Lake Orta after liming. J. Limnol. 60:69-78.

Canuto VM, Howard A, Cheng Y, Dubovikov MS, 2001. Ocean 
Turbulence. Part I: One-Point Closure Model-Momentum and Heat Vertical Diffusivities. J. Phys. Oceanogr. 31:14131426.

Caramatti I, Peeters F, Hamilton D, Hofmann H, 2020. Modelling inter-annual and spatial variability of ice cover in a temperate lake with complex morphology. Hydrol. Process. 34:691-704.

Carraro E, Guyennon N, Hamilton D, Valsecchi L, Manfredi EC, Viviano G, Salerno F, Tartari G, Copetti D, 2012. Coupling high-resolution measurements to a three-dimensional lake model to assess the spatial and temporal dynamics of the cyanobacterium Planktothrix rubescens in a medium-sized lake. Hydrobiologia 698:77-95.

Casulli V, Cheng RT, 1992. Semi-implicit finite difference methods for three-dimensional shallow water flow. Int. J. Numer. Meth. Fl. 15:629-648.

CH2011, 2011. Swiss climate change scenarios CH2011. C2SM, MeteoSwiss, ETH, NCCR Climate, and OcCC, Zurich, Switzerland: $88 \mathrm{pp}$.

Chapra SC, Reckow KH, 1983. Engineering Approaches for Lake Management - Volume 2: Mechanistic Modelling. Butterworth Publishers, Boston, USA: 492 pp.

Christensen V, Pauly D, 1992. ECOPATH II - a software for balancing steady-state ecosystem models and calculating network characteristics. Ecol. Model. 61:169-185.

Cole TM., Wells SA, 2013. CE-QUAL-W2: a two-dimensional, laterally averaged, hydrodynamic and water quality model, Version 3.71. User Manual, U.S. Army Corps of Engineers, Washington, USA.

Copetti D, Carniato L, Crise A, Guyennon N, Palmeri L, Pisacane G, Struglia M, Tartari G, 2013. Impacts of climate change on water quality, p. 307-332. In: A. Navarra and L. Tubiana (eds.), Regional Assessment of Climate Change in the Mediterranean. Springer.

Copetti D, Guyennon N, Buzzi F, 2020. Generation and dispersion of chemical and biological gradients in a large-deep multi-basin lake (Lake Como, north Italy): The joint effect of external drivers and internal wave motions. Sci. Total Environ. 749:141587.

Costanza R, Duplisea D, Kautsky U, 1998. Ecological Modelling on modelling ecological and economic systems with STELLA. Ecol. Model. 110:1-4.

Cuypers Y, Vinçon-Leite B, Groleau A, Tassin B, Humbert J-F, 2011. Impact of internal waves on the spatial distribution of Planktothrix rubescens (cyanobacteria) in an alpine lake. ISME J. 5:580-589.

Cyr H, 2017. Winds and the distribution of nearshore phytoplankton in a stratified lake. Water Res. 122:114-127.

Danis P-A, von Grafenstein U, Masson-Delmotte V, Planton S, Gerdeaux D, Moisselin J-M, 2004. Vulnerability of two European lakes in response to future climatic changes. Geophys. Res. Lett. 31:L21507.

Derot J, Yajima H, Jacquet S, 2020. Advances in forecasting harmful algal blooms using machine learning models: A case study with Planktothrix rubescens in Lake Geneva. Harmful Algae 99:101906.

Dietzel A, Mieleitner J, Kardaetz S, Reichert P, 2013. Effects of changes in the driving forces on water quality and plankton dynamics in three Swiss lakes - long-term simulations with BELAMO. Freshwater Biol. 58:10-35.
Dietzel A, Reichert P, 2012. Calibration of computationally demanding and structurally uncertain models with an application to a lake water quality model. Environ. Modell. Softw. 38:129-146.

Dissanayake P, Hofmann H, Peeters F, 2019. Comparison of results from two 3D hydrodynamic models with field data: internal seiches and horizontal currents. Inland Waters 9:239-260.

Dueri S, Castro-Jiménez J, Zaldívar J-M, 2009. Modelling the influence of thermal stratification and complete mixing on the distribution and fluxes of polychlorinated biphenyls in the water column of Ispra Bay (Lake Maggiore). Chemosphere 75:1266-1272.

Enz CA, Müller R, Mbwenemo Bia M, Heeb J, 2002. A population dynamics model for evaluating mortality factors in whitefish (Coregonus suidteri) larvae in Lake Hallwil. Adv. Limnol. 57:343-358.

Fenocchi A, Petaccia G, Sibilla S, 2016. Modelling flows in shallow (fluvial) lakes with prevailing circulations in the horizontal plane: limits of 2D compared to 3D models. J. Hydroinform. 18:928-945.

Fenocchi A, Rogora M, Marchetto A, Sibilla S, Dresti C, 2020. Model simulations of the ecological dynamics induced by climate and nutrient load changes for deep subalpine Lake Maggiore (Italy/Switzerland). J. Limnol. 79:221-237.

Fenocchi A, Rogora M, Morabito G, Marchetto A, Sibilla S, Dresti C, 2019. Applicability of a one-dimensional coupled ecological-hydrodynamic numerical model to future projections in a very deep large lake (Lake Maggiore, Northern Italy/Southern Switzerland). Ecol. Model. 392:38-51.

Fenocchi A, Rogora M, Sibilla S, Ciampittiello M, Dresti C, 2018. Forecasting the evolution in the mixing regime of a deep subalpine lake under climate change scenarios through numerical modelling (Lake Maggiore, Northern Italy/Southern Switzerland). Clim. Dyn. 51:3521-3536.

Fenocchi A, Rogora M, Sibilla S, Dresti C, 2017. Relevance of inflows on the thermodynamic structure and on the modeling of a deep subalpine lake (Lake Maggiore, Northern Italy/Southern Switzerland). Limnologica 63:42-56.

Finger D, Wüest A, Bossard P, 2013. Effects of oligotrophication on primary production in peri-alpine lakes. Water Resour. Res. 49:4700-4710.

Fornarelli R, Galelli S, Castelletti A, Antenucci JP, Marti CL, 2013. An empirical modeling approach to predict and understand phytoplankton dynamics in a reservoir affected by interbasin water transfers. Water Resour. Res. 49:3626-3641.

Fragoso CR, Motta Marques DML, Collischonn W, Tucci CEM, van Nes EH, 2008. Modelling spatial heterogeneity of phytoplankton in Lake Mangueira, a large shallow subtropical lake in South Brazil. Ecol. Model. 219:125-137.

Franchini F, Lepori F, Bruder A, 2017. Improving estimates of primary production in lakes: a test and a case study from a peri-alpine lake (Lake Lugano). Inland Waters 7:77-87.

Fringer OB, Gerritsen M, Street RL, 2006. An unstructured-grid, finite-volume, nonhydrostatic, parallel coastal ocean simulator. Ocean Model. 14:139-173.

Gallina N, Beniston M, Jacquet S, 2017. Estimating future cyanobacterial occurrence and importance in lakes: a case study with Planktothrix rubescens in Lake Geneva. Aquat. Sci. 79:249-263. 
Gallina N, Salmaso N, Morabito G, Beniston M., 2013. Phytoplankton configuration in six deep lakes in the peri-Alpine region: are the key drivers related to eutrophication and climate? Aquat. Ecol. 47:177-193.

García-Nieto PJ, García-Gonzalo E, Alonso Fernández JR, Díaz Muñiz C, 2018. Predictive modelling of eutrophication in the Pozón de la Dolores lake (Northern Spain) by using an evolutionary support vector machines approach. J. Math. Biol. 76:817-840.

Gaudard A, Räman Vinnä L, Bärenbold F, Schmid M, Bouffard D, 2019a. Toward an open access to high-frequency lake modeling and statistics data for scientists and practitioners - the case of Swiss lakes using Simstrat v2.1. Geosci. Model Dev. 12:3955-3974.

Gaudard A, Wüest A, Schmid M, 2019b. Using lakes and rivers for extraction and disposal of heat: Estimate of regional potentials. Renew. Energy 134:330-342.

Goudsmit G, Burchard H, Peeters, F, Wüest A, 2002. Application of $k-\varepsilon$ turbulence models to enclosed basins: The role of internal seiches. J. Geophys. Res. 107:23.

Gulliver JS, Stefan HG, 1982. Lake phytoplankton model with destratification. J. Env. Eng. Div.-ASCE 108:864-882.

Guyennon N, Valerio G, Salerno F, Pilotti M, Tartari G, Copetti $\mathrm{D}, 2014$. Internal wave weather heterogeneity in a deep multi-basin subalpine lake resulting from wavelet transform and numerical analysis. Adv. Water Resour. 71:149-161.

Hamilton DP, Schladow SG, 1997. Prediction of water quality in lakes and reservoirs. Part I - Model description. Ecol. Model. 96:91-110.

Henderson-Sellers B, 1986. Calculating the surface energy balance for lake and reservoir modelling: A review. Rev. Geophys. 24:625-649.

Hipsey MR, Bruce LC, Boon C, Busch B, Carey CC, Hamilton DP, Hanson PC, Read JS, De Sousa E, Weber M, Winslow LA, 2019. A General Lake Model (GLM 3.0) for linking with high-frequency sensor data from the Global Lake Ecological Observatory Network (GLEON). Geosci. Model Dev. 12:473-523.

Hipsey MR, Bruce LC, Hamilton DP, 2013. Aquatic EcoDynamics (AED) model library: science manual. AED Report. The University of Western Australia, Perth, Australia: 34 pp.

Hodges BR, Imberger J, Saggio A, Winters KB, 2000. Modeling basin-scale internal waves in a stratified lake. Limnol. Oceanogr. 45:1603-1620.

Huang J, Gao J, Hörmann G, 2012. Hydrodynamic-phytoplankton model for short-term forecasts of phytoplankton in Lake Taihu, China. Limnologica 42:7-18.

Huang J, Gao J, Hörmann G, Fohrer N, 2014. Modeling the effects of environmental variables on short-term spatial changes in phytoplankton biomass in a large shallow lake, Lake Taihu. Environ. Earth Sci. 72:3609-3621.

Huszar VLM., Caraco NF, Roland F, Cole J, 2006. Nutrientchlorophyll relationships in tropical-subtropical lakes: do temperate models fit? Biogeochemistry 79:239-250.

Hutter K, 1984. Hydrodynamics of lakes. CISM Courses and Lectures No. 286, Springer-Verlag, Wien: 341 pp.

Ibelings BW, Vonk M, Los HFJ, van der Molen DT, Mooij WM, 2003. Fuzzy modeling of cyanobacterial surface water blooms: validation with NOAA-AVHRR satellite images. Ecol. Appl. 13:1456-1472.
Imberger J, Loh I, Hebbert B, Patterson J, 1978. Dynamics of reservoir of medium size. J. Hydraul. Eng. Div.-ASCE 104:725-743.

Imberger J, Patterson JC, 1981. A dynamic reservoir simulation model - DYRESM: 5, p. 310-361. In: H.B. Fischer (ed.), Transport Models for Inland and Coastal Waters. Academic Press.

Jacob D, Bärring L, Christensen O, Christensen J, Castro M, Déqué M, Giorgi F, Hagermann S, Hirshi M, Jones R, Kjellström E, Lenderink G, Rockel B, Sànchez E, Schär C, Seneviratne SI, Somot S, val Ulden A, van den Hurk B, 2007. An inter-comparison of regional climate models for Europe: model performance in present-day climate. Clim. Change 81:31-52.

Janjua MY, Gerdeaux D, 2009. Preliminary trophic network analysis of subalpine Lake Annecy (France) using an Ecopath model. Knowl. Manag. Aquat. Ec. 392:02.

Joehnk KD, Umlauf L, 2001. Modelling the metalimnetic oxygen minimum in a medium sized alpine lake. Ecol. Model. 136:67-80.

Jung N-C, Popescu I, Kelderman P, Solomatine DP, Price RK, 2010. Application of model trees and other machine learning techniques for algal growth prediction in Yongdam reservoir, Republic of Korea. J. Hydroinf. 12:262-274.

Jurado E, Zaldívar J-M, Marinov D, Dachs J, 2007. Fate of persistent organic pollutants in the water column: Does turbulent mixing matter? Mar. Pollut. Bull. 54:441-451.

Kara EM, Hanson P, Hamilton D, et al., 2012. Time-scale dependence in numerical simulations: assessment of physical, chemical and biological predictions in a stratified lake at temporal scales of hours to months. Environ. Modell. Softw. 35:104-121.

Kerimoglu O, Jacquet S, Vinçon-Leite B, Lemaire BJ, Rimet F, Soulignac F, Trévisan D, Anneville O, 2017. Modelling the plankton groups of the deep, peri-alpine Lake Bourget. Ecol. Model. 359:415-433.

Kiefer I, Odermatt D, Anneville O, Wüest A, Bouffard D, 2015. Application of remote sensing for the optimization of in-situ sampling for monitoring of phytoplankton abundance in a large lake. Sci. Total Environ. 527-528:493-506.

Koschel R, Benndorf J, Proft G, Recknagel F, 1983. Calcite precipitation as a natural control mechanism of eutrophication. Arch. Hydrobiol. 98:380-408.

Krishna S, Ulloa HN, Kerimoglu O, Minaudo C, Anneville O, Wüest A, 2021. Model-based data analysis of the effect of winter mixing on primary production in a lake under reoligotrophication. Ecol. Model. 440:109401.

Laborde S, Antenucci JP, Copetti D, Imberger J, 2010. Inflow intrusions at multiple scales in a large temperate lake. Limnol. Oceanogr. 55:1301-1312.

Laborde S, Imberger J, Toussaint S, 2012. Contributions of local knowledge to the physical limnology of Lake Como, Italy. Proc. Natl. Acad. Sci. U.S.A. 109:6441-6445.

Lemaire M, Guillard J, Anneville O, Lobry J, 2020. Major biomass fluctuations in lake food webs - An example in the peri-alpine Lake Annecy. J. Great Lakes Res. 46:798-812.

Lepori F, Roberts JJ, 2015. Past and future warming of a deep European lake (Lake Lugano): What are the climatic drivers? J. Great Lakes Res. 41:973-981.

Lepori F, Roberts JJ, 2017. Effects of internal phosphorus load- 
ings and food-web structure on the recovery of a deep lake from eutrophication. J. Great Lakes Res. 43:255-264.

Lesser GR, Roelvink, JA, van Kester JATM, Stelling GS, 2004. Development and validation of a three-dimensional morphological model. Coast. Eng. 51:883-915.

Livingstone DM, 2003. Impact of secular climate change on the thermal structure of a large temperate Central European lake. Clim. Change 57:205-225.

Los FJ, Villars MT, Van der Tol MWM, 2008. A 3-dimensional primary production model (BLOOM/GEM) and its applications to the (southern) North Sea (coupled physical-chemical-ecological model). J. Marine Syst. 74:259-294.

Luyten PJ, Jones JE, Proctor R, Tabor A, Tett P, Wild-Allen K, 1999. COHERENS - A coupled hydrodynamical-ecological model for regional and shelf areas: User documentation. MUMM Report, Management Unit of the Mathematical Models of the North Sea, Brussels, Belgium: 914 pp.

Mari L, Biotto C, Decoene A, Bonaventura L, 2009. A coupled ecological-hydrodynamic model for the spatial distribution of sessile aquatic species in thermally forced basins. Ecol. Model. 220:2310-2324.

Mellor GL, Yamada T, 1982. Development of a turbulence closure model for geophysical fluid problems. Rev. Geophys. 20:851-875.

Messager ML, Lehner B, Grill G, Nedeva I, Schmitt O, 2016. Estimating the volume and age of water stored in global lakes using a geo-statistical approach. Nat. Commun. 7:13603.

Minella M, Leoni B, Salmaso N, Savoye L, Sommaruga R, Vione D, 2016. Long-term trends of chemical and modelled photochemical parameters in four Alpine lakes. Sci. Total Environ. 541:247-256.

Mirbach S, Lang U, 2018. Density-driven underflows with suspended solids in Lake Constance. J. Soils Sed. 18:31453152 .

Morillo S, Imberger J, Antenucci JP, Copetti D, 2009. Using impellers to distribute local nutrient loadings in a stratified lake: Lake Como, Italy. J. Hydraul. Eng.-ASCE 135:564574.

Moschet C, Götz C, Longrée P, Hollender J, Singer H, 2013. Multi-level approach for the integrated assessment of polar organic micropollutants in an international lake catchment: The example of Lake Constance. Environ. Sci. Technol. 47:7028-7036.

Müller B, Gächter R, Wüest A, 2014. Accelerated water quality improvement during oligotrophication in peri-alpine lakes. Environ. Sci. Technol. 48:6671-6677.

Neumann T, Fennel W, Kremp C, 2002. Experimental simulations with an ecosystem model of the Baltic Sea: A nutrient load reduction experiment. Glob. Biogeochem. Cycles 16:7.

Nouchi V, Kutser T, Wüest A, Müller B, Odermatt D, Baracchini T, Bouffard D, 2019. Resolving biogeochemical processes in lakes using remote sensing. Aquat. Sci. 81:27.

Nyholm N, 1978. A simulation model for phytoplankton growth and nutrient cycling in eutrophic, shallow lakes. Ecol. Model. 4:279-310.

Nürnberg GK, 1998. Prediction of annual and seasonal phosphorus concentrations in stratified and polymictic lakes. Limnol. Oceanogr. 43:1544-1552.

Oman G, 1982. [Das Verhalten des geschichteten Zürichsees unter äusseren Windlasten]. [Report in German]. Mitteilung Nr. 60 der Versuchsanstalt für Wasserbau, Hydrologie und Glaziologie, ETH Zürich, Zürich, Switzerland: 202 pp.

Omlin M, Brun R, Reichert P, 2001a. Biogeochemical model of Lake Zürich: sensitivity, identifiability and uncertainty analysis. Ecol. Model. 141:105-123.

Omlin M, Reichert P, Forster R, 2001b. Biogeochemical model of Lake Zürich: model equations and results. Ecol. Model. 141:77-103.

Oveisy A, Boegman L, Imberger J, 2012. Three-dimensional simulation of lake and ice dynamics during winter. Limnol. Oceanogr. 57:43-57.

Panizzuti M, Tartari G, 1995. $\mathrm{pH}$ simulation model in a mixed layer of a lacustrine environment (the case of Lake Orta). Ecol. Model. 78:37-49.

Patterson JC, Hamblin PF, 1988. Thermal simulation of a lake with winter ice cover. Limnol. Oceanogr. 33:323-338.

Paerl HW, Paul VJ, 2012. Climate change: Links to global expansion of harmful cyanobacteria. Water Res. 46:13491363.

Peeters F, Livingstone DM, Goudsmit G-H, Kipfer R, Forster $\mathrm{R}, 2002$. Modeling 50 years of historical temperature profiles in a large central European lake. Limnol. Oceanogr. 47:186-197.

Perroud M, Goyette S, Martynov A, Beniston M, Anneville O, 2009. Simulation of multiannual thermal profiles in deep Lake Geneva: A comparison of one-dimensional lake models. Limnol. Oceanogr. 54:1574-1594.

Piccolroaz S, Amadori M, Toffolon M, Dijkstra HA, 2019. Importance of planetary rotation for ventilation processes in deep elongated lakes: Evidence from Lake Garda (Italy). Sci. Rep. 9:8290.

Pilotti M, Simoncelli S, Valerio G, 2014a. A simple approach to the evaluation of the actual water renewal time of natural stratified lakes. Water Resour. Res. 50:2830-2849.

Pilotti M, Valerio G, Gregorini L, Milanesi L, Hogg CAR, 2014 b. Study of tributary inflows in Lake Iseo with a rotating physical model. J. Limnol. 73:115-129.

Pinardi M, Fenocchi A, Giardino C, Sibilla S, Bartoli M, Bresciani $\mathrm{M}, 2015$. Assessing potential algal blooms in a shallow fluvial lake by combining hydrodynamic modelling and remote-sensed images. Water 7:1921-1942.

Posch T, Köster O, Salcher MM, Pernthaler J, 2012. Harmful filamentous cyanobacteria favoured by reduced water turnover with lake warming. Nat. Clim. Change 2:809-813.

Råman Vinnå L, Bouffard D, Wüest A, Girardclos S, Dubois N, 2020. Assessing subaquatic mass movement hazards: an integrated observational and hydrodynamic modelling approach. Water Resour. Manag. 34:4133-4146.

Råman Vinnå L, Wüest A, Bouffard D, 2017. Physical effects of thermal pollution in lakes. Water Resour. Res. 53:3968-3987.

Razmi AM, Barry DA, Bakhtyar R, Le Dantec N, Dastgheib A, Lemmin U, Wüest A, 2013. Current variability in a wide and open lacustrine embayment in Lake Geneva (Switzerland). J. Great Lakes Res. 39:455-465.

Razmi AM, Barry DA, Lemmin U, Bonvin F, Kohn T, Bakhtyar $\mathrm{R}, 2014$. Direct effects of dominant winds on residence and travel times in the wide and open lacustrine embayment: Vidy Bay (Lake Geneva, Switzerland). Aquat. Sci. 76:59-71.

Reichert P, 1994. AQUASIM - A tool for simulation and data 
analysis of aquatic systems. Water Sci. Technol. 30:21-30.

Riley MJ, Stefan HG, 1988. Minlake: A dynamic lake water quality simulation model. Ecol. Model. 43:155-182.

Rinke K, Yeates P, Rothhaupt K-O, 2010. A simulation study of the feedback of phytoplankton on thermal structure via light extinction. Freshwater Biol. 55:1674-1693.

Rogora M, Buzzi F, Dresti C, Leoni B, Lepori F, Mosello R, Patelli M, Salmaso N, 2018. Climatic effects on vertical mixing and deep-water oxygen content in the subalpine lakes in Italy. Hydrobiologia 824:33-50.

Rossi G, Premazzi G, Marengo G, 1986. Correlation of a lake eutrophication model to field experiments. Ecol. Model. 34:167-189.

Saha GC, Felix M, Li J, Thring RW, 2011. Seasonal stratification effects on risk quantification of contaminant spreading in a warm monomictic lake under different hydrodynamic conditions: a case study in Lake Constance, Germany. Int. J. Risk Assess. Manag. 15:79-93.

Salmaso N, 2019. Effects of habitat partitioning on the distribution of bacterioplankton in deep lakes. Front. Microbiol. 10:2257.

Salmaso N, Anneville O, Straile D, Viaroli P, 2018. European large perialpine lakes under anthropogenic pressures and climate change: present status, research gaps and future challenges. Hydrobiologia 824:1-32.

Salmaso N, Buzzi F, Capelli C, Cerasino L, Leoni B, Lepori F, Rogora M, 2020. Responses to local and global stressors in the large southern perialpine lakes: Present status and challenges for research and management. J. Great Lakes Res. 46:752-766.

Salmaso N, Buzzi F, Cerasino L, Garibaldi L, Leoni B, Morabito G, Rogora M, Simona M, 2014. Influence of atmospheric modes of variability on the limnological characteristics of large lakes south of the Alps: a new emerging paradigm. Hydrobiologia 731:31-48.

Salmaso N, Morabito G, Mosello R, Garibaldi L, Simona M, Buzzi F, Ruggiu D, 2003. A synoptic study of phytoplankton in the deep lakes south of the Alps (lakes Garda, Iseo, Como, Lugano and Maggiore). J. Limnol. 62:207-227.

Salmaso N, Mosello R, Garibaldi L, Decet F, Brizzio MC, Cordella P, 2003. Vertical mixing as a determinant of trophic status in deep lakes: a case study from two lakes south of the Alps (Lake Garda and Lake Iseo). J. Limnol. 62:33-41.

Salmaso N, Mosello R, 2010. Limnological research in the deep southern subalpine lakes: synthesis, directions and perspectives. Adv. Oceanogr. Limn. 1:29-66.

Salvadè G, Stocker K, Trösch J, Zamboni F, 1992. Hydrodynamics of Lake Lugano. Aquat. Sci. 54:187-204.

Schauser I, Hupfer M, Brüggemann R, 2004. SPIEL_a model for phosphorus diagenesis and its application to lake restoration. Ecol. Model. 176:389-407.

Schauser I, Hupfer M, Brüggemann R, 2006. Sensitivity analysis with a phosphorus diagenesis model (SPIEL). Ecol. Model. 190:87-98.

Scheu KR, Fong D, Monismith SG, Fringer OB, 2018. Modeling sedimentation dynamics of sediment-laden river intrusions in a rotationally-influenced, stratified lake. Water Resour. Res. 54:4084-4107.

Schlabing D, Frassl MA, Eder MM, Rinke K, Bàrdossy A, 2014. Use of a weather generator for simulating climate change effects on ecosystems: A case study on Lake Constance. Environ. Modell. Softw. 61:326-338.

Schwefel R, Steinsberger T, Bouffard D, Bryant LD, Müller B, Wüest A, 2018. Using small-scale measurements to estimate hypolimnetic oxygen depletion in a deep lake. Limnol. Oceanogr. 63:S54-S67.

Simons TJ, 1981. The seasonal climate of the Upper Ocean: data analysis and model development. Technical Report. National Water Research Institute, Burlington: 72 pp.

Skamarock WC, Klemp JB, 2008. A time-split nonhydrostatic atmospheric model for weather research and forecasting applications. J. Comput. Phys. 227:3465-3485.

Soulignac F, Danis P-A, Bouffard D, Chanudet V, Dambrine E, Guénand Y, Harmel T, Ibelings BW, Trevisan D, Uittenbogaard R, Anneville O, 2018. Using 3D modeling and remote sensing capabilities for a better understanding of spatio-temporal heterogeneities of phytoplankton abundance in large lakes. J. Great Lakes Res. 44:756-764.

Spekat A, Kreienkamp F, Enke W, 2010. An impact-oriented classification method for atmospheric patterns. Phys. Chem. Earth 35:352-359.

Spraggs JD, Street RL, 1975. Three-dimensional simulation of thermally-influenced hydrodynamic flows. Technical Report Nr. 190, Department of Civil Engineering, Stanford University, Stanford, USA: 339 pp.

Stelling GS, Duinmeijer SPA, 2003. A staggered conservative scheme for every Froude number in rapidly varied shallow water flows. Int. J. Numer. Meth. Fl. 43:1329-1354.

Straile D, Kerimoglu O, Peeters F, 2015. Trophic mismatch requires seasonal heterogeneity of warming. Ecology 96:27942805.

Tiberti R, Caroni R, Cannata M, Lami A, Manca D, Strigaro D, Rogora M, 2021. Automated high frequency monitoring of Lake Maggiore through in situ sensors: system design, field test and data quality control. J. Limnol. 80:2011.

Tolotti M, Dubois N, Milan M, Perga M-E, Straile D, Lami A, 2018. Large and deep perialpine lakes: a paleolimnological perspective for the advance of ecosystem science. Hydrobiologia 824:291-321.

Trolle D, Hamilton DP, Hipsey MR, et al., 2012. A communitybased framework for aquatic ecosystem models. Hydrobiologia 683:25-34.

Trolle D, Jørgensen TB, Jeppesen E, 2008a. Predicting the effects of reduced external nitrogen loading on the nitrogen dynamics and ecological state of deep Lake Ravn, Denmark, using the DYRESM-CAEDYM model. Limnologica 38:220-232.

Trolle D, Skovgaard H, Jeppesen E, 2008b. The Water Framework Directive: Setting the phosphorus loading target for a deep lake in Denmark using the 1D lake ecosystem model DYRESM-CAEDYM. Ecol. Model. 219:138-152.

Ulloa HN, Constantinescu G, Chang K, Horna-Munoz D, Sepúlveda Steiner O, Bouffard D, Wüest A, 2019. Hydrodynamics of a periodically wind-forced small and narrow stratified basin: a large-eddy simulation experiment. Environ. Fluid Mechan. 19:667-698.

Ulrich MM, Imboden DM, Schwarzenbach RP, 1995. MASAS-A user-friendly simulation tool for modeling the fate of anthropogenic substances in lakes. Environ. Softw. 10:177-198. 


\section{Dresti et al.}

Valerio G, Cantelli A, Monti P, Leuzzi G, 2017. A modeling approach to identify the effective forcing exerted by wind on a prealpine lake surrounded by a complex topography. Water Resour. Res. 53:4036-4052.

Valerio G, Pilotti M, Barontini S, Leoni B, 2015. Sensitivity of the multiannual thermal dynamics of a deep pre-alpine lake to climatic change. Hydrol. Process. 29:767-779.

Vilhena LC, Marti CL, Imberger J, 2013. The importance of nonlinear internal waves in a deep subalpine lake: Lake Iseo, Italy. Limnol. Oceanogr. 58:1871-1891.

Vinçon-Leite B, 1991. [Contribution de la modélisation mathématique à l'étude de la qualité de l'eau dans les lacs subalpins: le lac du Bouget (Savoie)]. [Ph.D. Thesis in French]. Thèse de doctorat en Sciences Appliquées, Ecole Nationale des Ponts et Chaussées, Paris, France: 274 pp.

Vinçon-Leite B, Casenave C, 2019. Modelling eutrophication in lake ecosystems: A review. Sci. Total Environ. 651:29853001.

Vinçon-Leite B, Lemaire BJ, Khac VT, Tassin B, 2014. Longterm temperature evolution in a deep sub-alpine lake, Lake Bourget, France: how a one-dimensional model improves its trend assessment. Hydrobiologia 731:49-64.
Vinçon-Leite B, Tassin B, Jaquet J-M, 1995. Contribution of mathematical modeling to lake ecosystem understanding: Lake Bourget (Savoy, France). Hydrobiologia 300-301:433-442.

Wadzuk BM, Hodges BR, 2009. Hydrostatic versus nonhydrostatic Euler-equation modeling of nonlinear internal waves. J. Eng. Mech.-ASCE 135:1069-1080.

Weinberger S, Vetter M, 2012. Using the hydrodynamic model DYRESM based on results of a regional climate model to estimate water temperature changes at Lake Ammersee. Ecol. Model. 244:38-48.

Weinberger S, Vetter M, 2014. Lake heat content and stability variation due to climate change: coupled regional climate model (REMO)-lake model (DYRESM) analysis. J. Limnol. 73:93-105.

Wüest A, Bouffard D, Guillard J, Ibelings BW, Lavanchy S, Perga M-E, Pasche N, 2021. LéXPLORE: A floating laboratory on Lake Geneva offering unique lake research opportunities. Wiley Interdiscip. Rev. Water 8:e1544.

Yankova Y, Neuenschwander S, Köster O, Posch T, 2017. Abrupt stop of deep water turnover with lake warming: Drastic consequences for algal primary producers. Sci. Rep. $7: 13770$. 